\title{
Interactions between surface-bound actin and complement, platelets, and neutrophils
}

\author{
Jonas Wetterö, Agneta Askendal, Pentti Tengvall and Torbjörn Bengtsson
}

\section{Linköping University Post Print}

N.B.: When citing this work, cite the original article.

This is the authors' version of the final publication:

Jonas Wetterö, Agneta Askendal, Pentti Tengvall and Torbjörn Bengtsson, Interactions between surface-bound actin and complement, platelets, and neutrophils, 2003, Journal of Biomedical Materials Research, (66A), 1, 162-175.

http://dx.doi.org/10.1002/jbm.a.10591

Copyright: Wiley

Postprint available at: Linköping University Electronic Press

http://urn.kb.se/resolve?urn=urn:nbn:se:liu:diva-47776 


\title{
Interactions between surface bound actin and complement, platelets and neutrophils ${ }^{3}$
}

\author{
Jonas Wetterö $^{\mathrm{a}}{ }^{\mathrm{b}}{ }$, Agneta Askendal ${ }^{\mathrm{a}}$, Pentti Tengvall ${ }^{\mathrm{a}}$ and Torbjörn Bengtsson ${ }^{\mathrm{b}}$ \\ ${ }^{a}$ Division of Applied Physics, Department of Physics and Measurement Technology, Biology and \\ Chemistry, Linköping University, SE-581 83 Linköping, Sweden \\ ${ }^{b}$ Division of Medical Microbiology, Department of Molecular and Clinical Medicine, Faculty of Health \\ Sciences, Linköping University, SE-581 85 Linköping, Sweden \\ *Corresponding author \\ Fax: +4613 137568, phone: +4613282755 \\ E-mail address: jonwe@ifm.liu.se
}

Key words: reactive oxygen species, aggregation, biomaterials, cytoskeleton, plasma proteins

Running Title: Inflammatory reactions at surface bound actin

\footnotetext{
${ }^{3}$ No benefit of any kind will be received either directly or indirectly by the authors.
} 


\begin{abstract}
Actin exists as globular (G) monomers or polymeric filaments (F) in the cytoplasm of eukaryotic cells and mediates cell morphological changes and motility. Large amounts of this protein may be released out to the extracellular compartment during tissue injury, but little is known about its role in biomaterialrelated inflammation. We immobilized actin to methylated glass, methylated- and aminated silicon and gold model surfaces and studied subsequent blood serum deposition and complement activation, generation of reactive oxygen species (ROS), and adhesion and aggregation of neutrophils and platelets. Nullellipsometry shows that approximately one monolayer of G-actin can be immobilized onto the model surfaces and actin in buffer polymerizes on top of this by the addition of $\mathrm{K}^{+}$and $\mathrm{Mg}^{2+}$ ions to form a thicker layer of firmly bound F-actin. F-actin bound after serum incubation low amounts of anti-complement factor 1q (anti-C1q). The analysis of cell responses upon contact with actin-coated surfaces by luminol-amplified chemiluminescence, lumi-aggregometry and fluorescence microscopy show that surface-triggered aggregation, spreading, and generation of ROS were down-regulated and comparable to the response by adsorbed albumin. However, F-actin on gold surfaces recruited platelets in a C1q-dependent manner. We conclude that adsorbed actin in vitro is a weak complement, platelet and neutrophil activator, although Factin associates with both C1q and platelets.
\end{abstract}




\section{INTRODUCTION}

Protein adsorption precedes the adhesion of cells to artificial surfaces. The composition and thickness of the adsorbed protein layer may vary over time depending on the surface characteristics, ${ }^{1}$ but is believed to play an important role for the behavior of early appearing inflammatory cells such as platelets and neutrophil granulocytes. It is well known that the surface deposition of fibrin/fibrinogen, coagulation proteins, and the activation of the complement system may amplify the acute inflammatory response (reviewed by Tang and Eaton ${ }^{2}$ ). Complement is a humoral part of the defense against infection and acts by perforation of bacterial cell walls, recruitment of leukocytes and facilitation of phagocytosis through opsonization of natural as well as artificial surfaces. ${ }^{3}$ There exist in principle two routes to activate complement at artificial surfaces: $i$ ) a rapid ${ }^{4}$ activation induced by surface deposited immunoglobulins and complement facor 1q (C1q) (classical activation) or ii) a slower ${ }^{4}$ activation on nucleophilic surface groups that form ester or amide bonds with complement factor 3 (C3) (alternative activation). The latter mechanism has been described as the main activation mechanism at artificial surfaces, ${ }^{5-7}$ although recent studies reveal that also the classical pathway is indeed relevant for biomaterials. ${ }^{8-10}$

The cytoskeletal protein actin $(42 \mathrm{kDa})$ is among the most abundant proteins in the human body and is a key protein in cell morphological changes and motility. Actin represents $10-30 \%$ of the intracellular protein content of eukaryotic cells and in the neutrophil peripheral cytoplasm the concentration may locally be approximately $20 \mathrm{mg} / \mathrm{mL}^{11}$ It is also found in the extracellular compartment, especially after tissue injury, and micromolar concentrations have then been reported. ${ }^{12-14}$ Despite this, biocompatibility and protein adsorption studies have been performed almost exclusively using plasma proteins and until date little is known about the effects of adsorbed actin. This protein exists in the form of globular monomers (G-actin) or filamentous polymers (F-actin). G-actin can be polymerized to F-actin in the presence of adenosine triphosphate (ATP) and cations such as $\mathrm{Mg}^{2+}$ and $\mathrm{K}^{+}$. Others and we have demonstrated that the adhesion of neutrophils and platelets to artificial surfaces is associated with a rapid and extensive actin polymerization, ${ }^{15-17}$ leading to spreading and possibly also frustrated phagocytosis and necrosis. The osmotic conditions in the extracellular compartment favor F- before G-actin. However, in order to avoid the harmful effects of free actin in circulation, blood plasma contains a regulatory system of 
specific actin binding proteins. Plasma gelsolin shortens actin filaments and vitamin D binding protein (Gcglobulin) sequesters G-actin under physiological calcium concentrations. ${ }^{18}$ The synthesis rate of the regulatory proteins increases after tissue injury. ${ }^{19}$ Actin may adsorb to various surfaces, ${ }^{20}$ and Renault $e t$ al. demonstrated in vitro surface polymerization of actin. ${ }^{21}$ However, little is known about how the early inflammatory response is affected by surface immobilized actin.

Several reports suggest a direct interaction between actin and humoral systems that affect cell behavior. Serum spiked with G-actin was shown to be toxic to pulmonary endothelial cells, possibly due to complement activation, ${ }^{22}$ and vitamin D-binding protein enhanced the chemotactic effects of C5a (reviewed by Haddad ${ }^{23}$ ). A direct binding of actin to C1q, ${ }^{24}$ immunoglobulins (IgG and IgM), ${ }^{25}$ and fibrin clots ${ }^{26}$ (and between fibrin clots and gelsolin ${ }^{27}$ ) have been reported. Furthermore, it was shown in cell-free systems that actin enhances ROS generation from the isolated NADPH oxidase system ${ }^{28}$ that is abundant in leukocytes ${ }^{29}$ and possibly also in platelets. ${ }^{30}$ F-actin is suggested to be able to activate platelets, probably by presenting adenosine diphosphate (ADP) to ADP-receptors leading to intracellular actin polymerization. ${ }^{31}$

In the present study we utilized an in vitro model system to elucidate serum plasma and complement binding properties, and platelet and neutrophil granulocyte responses to surface bound actin.

\section{MATERIALS AND METHODS}

\section{Reagents, antibodies, sera and plasma}

All chemicals were from Sigma Chemical Co. (St. Louis, MO) and of analytical grade if not otherwise stated. The polyclonal rabbit antibodies used during ellipsometry studies were IgG-fractions of polyclonal anti-human A 0062 (anti-C3c), A 0136 (anti-C1q), A 0063 (anti-C3d), A 424 (anti-IgG, specific for $\gamma$-Chains), A 0001 (anti-albumin) and A 0080 (anti-fibrinogen, that also reacts against fragments D and E(1)) from Dakopatts (Glostrup, Denmark). The polyclonal sheep anti-human PC115 (anti-high molecular weight kininogen, anti-HMWK) and PC116 (anti-properdin) were delivered by The Binding Site Ltd. (Birmingham, U.K.). Blood was drawn from non-medicated apparently healthy volunteers, and pooled 
normal human serum (NHS) and heparinized plasma were prepared according to standard protocols and stored below $-70^{\circ} \mathrm{C}$ until use. C1q-depleted serum and purified C1q were from Quidel Corp. (San Diego, CA, USA). The C1q-depleted serum was reconstituted with $180 \mu \mathrm{g} / \mathrm{mL}$ C1q. 32

\section{Model surfaces}

Flat silicon wafers from Wacker-Chemie GmbH (München, Germany) cleaved in the (100) crystal direction into $5 \times 10 \mathrm{~mm}$ pieces, or $40 \times 8 \mathrm{~mm}$ glass (approximately $75 \% \mathrm{SiO}_{2}$ ) test tubes (Assistent $\mathrm{KHG}$, Sondheim-Rhön, Germany), were cleaned from organic contaminations during $5 \mathrm{~min}$ at $80^{\circ} \mathrm{C}$ in $5: 1: 1$ parts of distilled water, hydrogen peroxide $(30 \% \mathrm{v} / \mathrm{v})$ and $\mathrm{NH}_{4} \mathrm{OH}(25 \% \mathrm{v} / \mathrm{v})$. After ten rinsings in distilled water, the inorganic contaminations on substrates were removed by 5 min at $80^{\circ} \mathrm{C}$ in $6: 1: 1$ parts of distilled water, hydrogen peroxide $(30 \% \mathrm{v} / \mathrm{v})$ and hydrochloric acid $(37 \% \mathrm{v} / \mathrm{v})$. This yields a thin hydrated surface layer of $\mathrm{SiO}_{2} 33,34$ (water/surface static contact angle, $\theta_{\mathrm{w}},<10^{\circ}$, when measured with a Ramé-Hart NRL Model 100 goniometer, USA).

The hydrophilic substrates were excessively washed in water, 99.5\% (v/v) ethanol and xylene (Merck KGaA, Darmstadt, Germany), and methylated during 5 min in 1\% (v/v) dichlorodimethylsilane $\left(\mathrm{Cl}_{2}\left(\mathrm{CH}_{3}\right)_{2} \mathrm{Si}\right)$ in xylene at room temperature. Silane contamination traces were eliminated by rinsings in xylene, ethanol, and finally sonicated for $1 \mathrm{~min}$ in xylene (Sondrex RK100 (Bandelin Electronics, Berlin, Germany). The methylated $\mathrm{SiO}_{2}$-surfaces were hydrophobic $\left(\theta_{\mathrm{w}}>90^{\circ}\right)$ and stored in xylene for less than one week. The silicon surfaces were used primarily in ellipsometry studies and glass surfaces in blood cell experiments.

Cleaned hydrophilic silicon wafers were dried and placed in a chamber containing $200 \mu \mathrm{l}$ aminopropyl-triethoxysilane (APTES, Merck KGaA). The surfaces were then vapor aminated during $10 \mathrm{~min}$ at $60^{\circ} \mathrm{C}$ in low vacuum (6 mtorr), followed by extended baking during $60 \mathrm{~min}$ at $150^{\circ} \mathrm{C}$ in low vacuum. The APTES-coated surfaces were rinsed in xylene, ethanol, and sonicated for $1 \mathrm{~min}$ in xylene. The layer thickness was approximately 20 Ångströms $\left(1 \AA=1 \times 10^{-10} \mathrm{~m}\right)$ and the surfaces were stored in xylene until use in ellipsometry experiments. Similarly aminated (amino-propyl-trimethoxysilane, APTMS) silicon particles with average diameter of $20 \mu \mathrm{m}$ (non-phagocytosable size for neutrophils) were purchased from 
Gerlinde Kisker GbR (Steinfurt, Germany) for use in lumi-aggregometry experiments. Aminated particles or flat silicon were incubated for $30 \mathrm{~min}$ in $6 \%$ glutaraldehyde (GA; Merck KGaA) at room temperature in phosphate buffered saline (PBS, buffer composition as stated below but $\mathrm{pH}$ 9). ${ }^{35}$, 36 For particles, each rinsing step was followed by a 5 min centrifugation at $300 \mathrm{x}$ g.

Glass slides (9 x 9 mm, Biacore AB, Uppsala, Sweden) were sputter coated with $2000 \AA$ gold, and cleaned during 5 min in ozone and ultraviolet light in a UVO-cleaner (Model 42-220, Jelight Company Inc., Irvine, CA). The clean gold surfaces were then immediately transferred to a protein containing buffer $\left(37^{\circ} \mathrm{C}\right)$. The protein coated gold surfaces were subsequently used in both ellipsometry and blood cell studies.

\section{Protein adsorption}

The model surfaces were washed at least three times in respective coating buffer and a monolayer of normal human plasma IgG, albumin (both from Pharmacia \& UpJohn, Stockholm, Sweden) or rabbit muscle G-actin (Molecular Probes, Inc., Eugene, OR, product number A-12375) was adsorbed during $\geq 1$ hour of incubation at room temperature (gold surfaces at $37^{\circ} \mathrm{C}$ ) in $0.1 \mathrm{mg} / \mathrm{mL}$ of protein in a suitable buffer, followed by duplicate rinsings in buffer. Phosphate buffered saline (PBS; $10 \mathrm{mM}$ sodium hydrogen phosphate, $10 \mathrm{mM}$ potassium dihydrogen phosphate and $0.15 \mathrm{M}$ sodium chloride, $\mathrm{pH}$ 7.3) was used as the buffer during albumin and IgG depositions, and $2.0 \mathrm{mM}$ Tris (pH 8.0) for G-actin. After the protein coating step, all experiments were performed at $37^{\circ} \mathrm{C}$. In order to discriminate between a spontaneous protein adsorption and covalent immobilization in the control experiments, the samples were incubated for $30 \mathrm{~min}$ at $37^{\circ} \mathrm{C}$ in sodium dodecyl sulfate (SDS, $10.4 \mathrm{mM}$ ) in PBS. ${ }^{37}$ In some experiments, $\mathrm{Ca}^{2+}$ and/or $\mathrm{Mg}^{2+}$ were chelated in NHS by $10 \mathrm{mM}$ ethylene-diamine-tetraacetic acid (EDTA) and ethylene-glycol-tetraacetic acid (EGTA; both from Merck KGaA). In F-actin surface control experiments, the actin polymerization stabilizer jasplakinolide (Molecular Probes) was used. Plasma protein coated APTMS-particles were endotoxin negative (Limulus Amebocyte Lysate Coatest, Charles River Endosafe, Charleston, SC). Polyclonal anti-albumin antibodies did not bind to actin-coated surfaces, indicating that the purified actin 
contained low amounts of albumin (important since albumin-coated surfaces were used as a reference for actin-coated surfaces).

\section{Ellipsometry}

Flat silicon and gold surfaces were illuminated at a $70^{\circ}$ angle of incidence with elliptically polarized light (HeNe laser, $\lambda=6328 \AA$ ) in an AutoEl III ellipsometer (Rudolf Research, NJ). By recording the ellipsometric angles $\Delta$ and $\psi$ before adsorption and by finding new $\psi$ and $\Delta$ after adsorption, the thickness of deposited surface films could be iterated according to the McCrackin evaluation algorithm. ${ }^{38}$ The protein refractive index $(\mathrm{N})$ was assumed to be $\mathrm{N}_{\text {film }}=1.465$. The adsorbed surface film thickness was converted to deposited mass per unit area according to de Feijter et al. ${ }^{39}$ Experiments with methylated or aminated silicon surfaces and NHS or heparinized plasma were performed at $37^{\circ} \mathrm{C}$ in veronal buffered saline $\left(\mathrm{VBS}^{2+}\right.$; 5 mM 5,5'-dietylbarbituric acid, the corresponding sodium salt, $145 \mathrm{mM}$ sodium chloride, $0.15 \mathrm{mM} \mathrm{CaCl}_{2}$ and $0.5 \mathrm{mM} \mathrm{MgCl}_{2}, \mathrm{pH} 7.4$ ) and analyzed in air. The ellipsometric experiments on gold were performed in situ in a cuvette with assumed buffer refractive index $N_{\text {buffer }}=1.335 .8,40$ Generally, the IgG-, albumin- and actin-coated model surfaces were incubated in 10\% NHS or plasma for both 5 and 90 min. A short interaction allows detection of surface deposited complement components of the classical activation pathway, whereas an alternative pathway activation is primarily recognized after a long interaction. 4, 8, 41 The protein solutions were exchanged for polyclonal antibodies in PBS at 1/50 dilutions for $30 \mathrm{~min}$ for the detection of selected proteins in the adsorbed NHS or plasma films. ${ }^{4,}$, 41

\section{Blood cells}

Peripheral blood was drawn from apparently healthy non-medicated blood donors at the Linköping University Hospital. The blood was anti-coagulated by $5 \mathrm{IU} / \mathrm{mL}$ heparin. Calcium was excluded from all buffers during the cell separations, but reconstituted through the addition of $1.1 \mathrm{mM} \mathrm{CaCl}{ }_{2}$ before the experiments. Neutrophil granulocytes (with $<0.1$ platelet per neutrophil) were prepared according to the 
methodology of Böyum and others. ${ }^{42-44}$ One part of fresh whole blood was layered on one part of Lymphoprep over four parts of Polymorphprep (Nycomed Pharma AS, Oslo, Norway) in $50 \mathrm{~mL}$ test tubes, which were immediately centrifuged at room temperature for $40 \mathrm{~min}$ at $480 \mathrm{x}$. The resulting middle band containing neutrophils was harvested. The neutrophil fraction was washed in room tempered PBS for 10 min at $480 \times \mathrm{g}$, and the remaining red cells were eliminated by brief hypotonic lysis at $4^{\circ} \mathrm{C}$ followed by washing (200 $\mathrm{x} g$ at $4^{\circ} \mathrm{C}$ ) in Krebs-Ringer phosphate buffer supplemented with $10 \mathrm{mM}$ glucose and 1.5 $\mathrm{mM} \mathrm{MgSO}_{4}$, $\mathrm{pH} 7.3$ (KRG). The neutrophils were kept at $4^{\circ} \mathrm{C}$ until pre-warming to $37^{\circ} \mathrm{C}, 5 \mathrm{~min}$ before the experiments. The number of neutrophils per unit volume and the purity of the preparations were analyzed in a Coulter Counter ZM Channelyser 256 (Coulter-Electronics Ltd., Luton, UK).

The platelets were prepared at room temperature by collection of platelet rich plasma after $20 \mathrm{~min}$ of centrifugation (220 x g) of whole blood mixed with $17 \%(\mathrm{v} / \mathrm{v})$ of an acid-citrate-dextrose solution (85 $\mathrm{mM}$ sodium citrate, $71 \mathrm{mM}$ citric acid and $111 \mathrm{mM}$ glucose). The platelets were then isolated through centrifugation of the platelet rich plasma $(480 \mathrm{x} g)$ for $20 \mathrm{~min}$, followed by removal of the plasma and gentle washing and resuspension of the cells in KRG. ${ }^{45}$ The platelet count was determined with a Bürker chamber, and the cells displayed no apparent aggregation or morphological changes due to the preparation procedure.

\section{Chemiluminescence and aggregation}

The generation of ROS during cellular interaction with the model surfaces was studied by luminol-amplified chemiluminescence (CL; reviewed by Dahlgren et al. ${ }^{46}$ ). The CL-response in methylated glass test tubes was analyzed in $4 \mathrm{~mL}$ cuvettes in a six-channel Biolumat (LB 9505 C, Berthold Co., Wildbaden, Germany), as previously described. 47,48 The tubes contained pre-warmed solutions of platelets and/or neutrophils, $4 \mathrm{U} / \mathrm{mL}$ horseradish peroxidase (Boehringer Mannheim GmbH, Mannheim, Germany) and $50 \mu \mathrm{M}$ luminol (5-amino-2,3-dihydro-1,4-phtalazinedione) in KRG. The ROS-production induced by APTMS-particles was detected essentially as above, but under stirring conditions in a twosample Lumi-Aggregometer model 560 (Chrono-Log Corp., Havertown, PA) according to a recent protocol. ${ }^{49}$ The Lumi-Aggregometer records, simultaneously with CL, increase in light transmission, as 
occurs when cells and particles aggregate. Reagents and cells were equilibrated for 5 min in polystyrene cuvettes (\#367) at $37^{\circ} \mathrm{C}$ under stirring (700 rpm; stir bar \#370). The optical channels were immediately set to baseline after the addition of $1 \times 10^{5} / \mathrm{mL}$ APTMS-particles. The CL data were exported and integrated by the KaleidaGraph 3.5 software (Synergy Software, Reading, PA).

\section{Cell adhesion and morphology}

Neutrophils and/or platelets were allowed to interact with protein-coated gold surfaces with or without the presence of NHS. The cells were then fixed for $30 \mathrm{~min}$ in $4 \%$ ice-cold paraformaldehyde in PBS. The samples were washed twice in PBS and the cells permeabilized and stained for F-actin through incubation in $100 \mu \mathrm{g} / \mathrm{mL}$ lysophosphatidylcholine and $0.6 \mu \mathrm{g} / \mathrm{mL}$ bodipy-phallacidin (Molecular Probes) in PBS for 30 min at room temperature in darkness. The staining solution was removed by duplicate washings in PBS. The samples were mounted in Dako fluorescence mounting medium (Dakopatts) and the cell morphology and adhesion was studied in a Zeiss Axioscope (Carl Zeiss, Oberkochen, Germany) at $630 \mathrm{x}$ original magnification. The documentation was made with a Carl Zeiss ZVS-47E digital camera, or by manual counting of the number of adhered cells in at least 25 microscopic views per sample. Key samples were evaluated independently by two persons. Original pictures were generated at a constant gain using the Easy Image Measurement 2000 software (version 2.3, Bergström Instrument AB, Solna, Sweden). Sparse editing of pictures (all images treated similarly) was performed with Canvas 5.0 software (Deneba Systems, Inc., Miami, FL). Importantly, G- or F-actin coated surfaces did not show enhanced fluorescence after staining with bodipyphallacidin (compared to non-coated gold surfaces), probably since metal films quench fluorescence near the surface. ${ }^{50}$

\section{Statistics}

The data were assumed Gaussian distributed and are presented as mean \pm SEM. $n$ denotes the number of independent experiments, and in blood cell experiments the number of individual blood donors. The statistical evaluation was performed using the two-tailed paired Student's $t$-test. The significance notations in illustrations represent the conventional significance levels $*(\mathrm{p}<0.05),{ }^{* *}(\mathrm{p}<0.01),{ }^{* * *}$ $(\mathrm{p}<0.001)$ and NS (not significant). 


\section{RESULTS}

\section{Actin immobilization}

Surfaces were incubated in $0.1 \mathrm{mg} / \mathrm{mL}$ actin and the ellipsometric thickness was approximately $9 \AA$ on methylated surfaces, $5 \AA$ on aminated silicon and $16 \AA$ on gold. Upon addition of $100 \mathrm{mM} \mathrm{K}{ }^{+}$and $2 \mathrm{mM}$ $\mathrm{Mg}^{2+}$ to the actin solution, a rapid additional deposition of actin was induced at gold surfaces, reaching saturation at approximately $40 \AA$ during one hour of incubation (Fig. 1). When the same procedure was applied on G-actin on aminated silicon, a similar protein layer thickening process was observed (not shown). The rapid deposition indicated a polymerization process on top of the initial actin film and formation of F-actin. Only a minor part $(\leq 10 \AA)$ of this F-actin layer could be removed by in situ rinsings in SDS solution or by extended incubations in the buffer (without $\mathrm{K}^{+}$and $\mathrm{Mg}^{2+}$ ). In cases where the F-actin layer was first stabilized by jasplakinolide ( $0.1 \mu \mathrm{M}$ for $5 \mathrm{~min})$, it became completely unaffected by subsequent rinsings. The thickness of the F-actin layer could not be affected by elutions in SDS, or addition of $10 \mathrm{mM}$ EDTA or extra adenosine triphosphate (ATP). The adsorbed G-actin on methylated surfaces was easily removed by SDS, whereas the G-actin layer remained intact on aminated silicon and gold, indicating a covalent (or equivalent to covalent) protein immobilization in the latter cases. The thickness of the Gactin layer was comparable to the thickness of albumin films, but thinner than IgG films (see Fig. 2-3).

\section{Complement on silicon}

Immobilized G- and F-actin layers on aminated silicon adsorbed proteins during incubations in $10 \%$ NHS or heparinized plasma, and the layer thickening was larger than $10 \AA$ after 5 min of incubation (Table 1, Fig. 2A-B data group I and Fig. 3). Spontanously adsorbed G-actin on methylated silicon bound

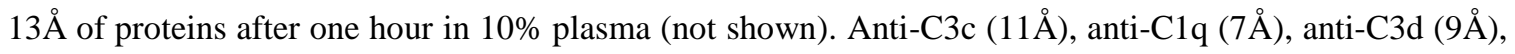

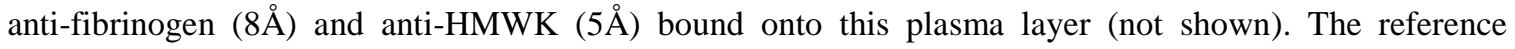


plasma layer on non-coated methylated silicon bound close to identical amounts of anti-fibrinogen $(10 \AA)$ and anti-HMWK (4§) compared to the G-actin surface, but the binding of anti-C3c, anti-C1q and anti-C3d were reduced by approximately $46 \%, 57 \%$ and $33 \%$, respectively (not shown). For this reason, further analysis was focused on the evaluation of complement binding to immobilized actin on aminated silicon and pure gold surfaces.

Covalently immobilized G-actin on aminated silicon bound approximately $22 \AA$ and $45 \AA$ of proteins after 5 and 90 min incubations in 10\% NHS, respectively (Fig. 2A, data groups I and II, and Table 1). A significant increase in layer thicknesses was observed upon subsequent incubations in anti-C1q (13A

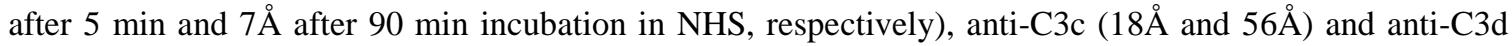

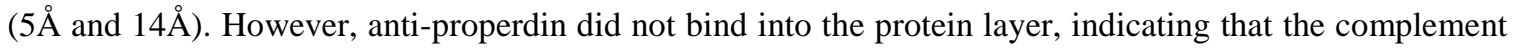
protein deposition was not due to a sustained classical activation since properdin stabilizes C3- and C5convertases and serves as a marker of prolonged surface activation of complement. Thus, the half-life time of the convertases was too short to present any detectable amounts of properdin in the serum layer. Alternatively, sterical hindrances made it impossible for the antibodies to bind to properdin.

F-actin on aminated silicon surfaces bound $11 \AA$ and $18 \AA$ of serum after 5 and 90 min incubations, respectively (Fig. 2B, group I and II, and Table 1). C1q, C3c and C3d could be identified by polyclonal antibodies in this film (significant depositions of $9 \AA$ and $5 \AA$ anti-C1q, $7 \AA$ and $46 \AA$ anti-C3c, and $6 \AA$ and $12 \AA$ anti-C3d after 5 and 90 min NHS incubation, respectively). The serum incubated F-actin surface did not bind anti-properdin.

The serum deposition to immobilized albumin (recognized as a low activator in the literature) on aminated silicon was comparable to that for immobilized G-actin, $19 \AA$ after 5 min and $36 \AA$ after 90 min of

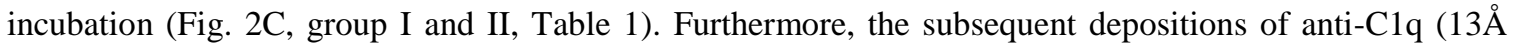

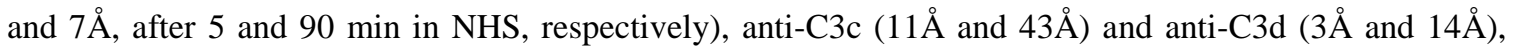
with no binding of anti-properdin, suggests that covalently immobilized albumin as well as actin on aminated silicon are weak or moderate activators of the complement system. Studies on serum protein deposition to IgG on aminated silicon, $9 \AA \AA$ and $40 \AA$ after 5 and 90 min incubation, respectively (Fig. 2D and 
Table 1), show that the antibody binding was higher but not very different from that observed on albumin-

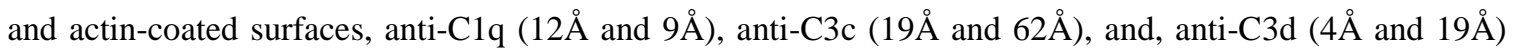
after 5 and 90 min incubations in NHS, respectively. However, the IgG-surfaces showed the largest serum binding after the prolonged incubation and the highest subsequent binding of anti-C3c and anti-C3d. Furthermore, only IgG-surfaces bound appreciable amounts of anti-properdin, $7 \AA$ after the 90 min NHS incubation. Since bare aminated glutaraldehyde treated surfaces also have the capacity to bind C1q, C3c and C3d after 90 min of serum incubation (Table 1 and Fig. 2E), the analysis of interactions between C1q and actin required yet another base surface. Actin was therefore spontaneously adsorbed to gold.

\section{Complement on gold}

The serum layer thickness at G-actin on gold was approximately $33 \AA$ after 5 min of incubation (Fig. 3, data group I). The corresponding F-actin layer thickness was $25 \AA$ (Fig. 3, group II), albumin on

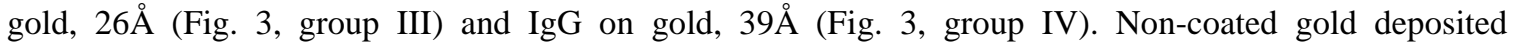
approximately $40 \AA$ serum upon incubation in a similar way (not shown). No significant amounts of antiC1q bound to the serum layers on G-actin (Fig. 3, group I), albumin (group III) or IgG (group IV). However, small amounts of anti-C1q bound to serum incubated G-actin, and when G-actin was replaced for F-actin a significant binding of approximately $9 \AA$ anti-C1q occurred (Fig. 3, group III). In order to confirm that the anti-C1q binding was not a result of a non-specific binding to F-actin, control experiments with C1q-depleted serum were performed. No anti-C1q bound to the protein layers when actin-, albumin-, IgG-, or non-coated surfaces were incubated for $5 \mathrm{~min}$ in 10\% C1q-depleted serum (Table 1). When the depleted serum was reconstituted with C1q approximately three times more anti-C1q bound to serum incubated Factin surfaces $(27 \AA)$, compared to the other three surfaces $(\leq 11 \AA$, Table 1$)$. Is $\mathrm{C} 1 \mathrm{q}$ and the classical activation pathway then necessary for the deposition of C3? Approximately 13A anti-C3c bound to F-actin after a 5 min NHS incubation, and this deposition disappeared completely upon the addition of EGTA to the serum. The anti-C1q binding remained intact on F-actin surfaces after incubations in EGTA-serum. This is in accordance with earlier studies showing that the assembly of the C1-complex is $\mathrm{Ca}^{2+}$-dependent, but the surface binding of $\mathrm{C} 1 \mathrm{q}$ is not. The results show that $\mathrm{C} 1 \mathrm{q}$ is important for the deposition of $\mathrm{C} 3$ on Factin. Despite this, it is important to note that the anti-C3c binding to NHS films on F-actin surfaces was 
relatively low. In comparison, the NHS protein layer on IgG and albumin bound approximately $63 \AA$ and $32 \AA$ of anti-C3c, respectively, and the depositions disappeared after addition of EGTA to the serum. In summary, actin surfaces are poor complement system activators, although F-actin sequesters C1q. Double diffusion Ouchterloney test of soluble actin and C1q in agarose showed no precipitation line (not shown).

\section{Chemiluminescence}

No direct or primed ROS generation was observed upon stimulation of the neutrophils with 10 $\mu \mathrm{g} / \mathrm{mL}$ soluble actin (measured as luminol-amplified chemiluminescence (CL) with or without a second stimulation of $0.1 \mu \mathrm{M}$ formyl-Met-Leu-Phe). G-actin precoated hydrophobic glass surfaces reduced the neutrophil CL by approximately 43\% (Fig 4), and the response was further decreased by $81 \%$ when NHS (5\%) was added to the cell solution (not shown). This is similar to the ROS generation on low-activator surfaces such as spontaneously adsorbed albumin, but very different from the potent neutrophil ROS generation triggered e.g. by immobilized IgG during NHS incubations. ${ }^{47}$ In contrast to the previously reported potentiating effects of activated platelets on the neutrophil ROS-production on IgG-coated surfaces, $49,51,52$ the introduction of platelets to neutrophils that contacted G-actin induced no amplification of the total CL-response, quite similar to albumin surfaces (Fig. 4).

The ROS generation was studied after stimulation of the cells with protein-coated aminated silicon particles under stirring conditions in a Lumi-Aggregometer. The results correlate well with similar results on methylated surfaces. The neutrophil CL-response remained low on G-actin on aminated silicon particles. Reference IgG-coated particles on the other hand activated the neutrophil respiratory burst via $\mathrm{F}_{\mathrm{c \gamma}}$-receptors (Fig. 5A). ${ }^{49}$ In general, the neutrophil CL-response on G-actin coated particles was not significantly different from that of albumin-coated particles (Fig. 5A-C), and the response became almost totally quenched with the introduction of 5\% NHS to the cell solution (Fig. 5B). This indicates that the observed complement deposition was not a result of a true or prolonged complement activation since the actin- and 
albumin-coated surfaces gave rise to low neutrophil respiratory burst responses in serum containing media. Furthermore, the introduction of platelets to the neutrophil test system showed no effect on the total ROS generation in response to G-actin or albumin particles (Fig. 5C), providing further support for the hypothesis that surface bound actin is a poor activator of the inflammatory response.

\section{Cell-particle aggregation}

The platelet is a specialized wound healing and hemostasis cell, but possess also potent inflammatory capabilities. Platelets aggregate upon activation and this can serve as a marker for the degree of activation. For example, surface bound IgG is a moderate activator of aggregation (via the $\mathrm{F}_{\mathrm{c} \gamma}$-receptor) and shows approximately one third of the aggregation response that is induced by collagen. 49 The aggregation by G-actin particles was approximately one third of that of IgG-coated particles (Fig. 6A), and

did not differ significantly from that of albumin coated particles (Fig. 6A-B). Hence, the platelet binding to G-actin was low. Similar findings were observed for neutrophils or mixtures (at a physiological ratio) of neutrophils and platelets (Fig. 6B). Since the particle-based measurement system was not a useful tool for the study of responses by F-actin coated particles (the particles aggregated during the polymerization stage), the influence of F-actin on the platelet and neutrophil behavior was primarily evaluated by the use of morphological methods.

\section{Cell adhesion and morphology}

Neutrophils and/or platelets were fixed and F-actin stained after interactions with gold surfaces and evaluated by fluorescence microscopy. Adhered neutrophils (Fig. 7) and platelets (Fig. 8) demonstrated an extensive spreading that was reduced by coating the surfaces with G- or F-actin. The presence of $5 \%$ NHS did not cause any quantitative or morphological changes in the neutrophil adhesion on G- or F-actin, 
but inhibited the binding and spreading on non-coated surfaces (Fig. 7). Neutrophils that interacted with immobilized IgG displayed the opposite, i.e. an enhanced binding and spreading in serum containing buffer (Fig. 7). When NHS was exchanged for C1q-depleted serum, no difference regarding the neutrophil adhesion to actin-coated surfaces was observed (not shown). Platelets reacted, in contrast to neutrophils, with a reduced adhesion to G-actin, F-actin and non-coated gold when NHS was introduced (not shown, essentially like the reconstituted serum in Fig. 8). Furthermore, the number of adhered platelets on NHSopsonized F-actin was reduced by 37\% in C1q depleted serum (Fig. 8-9). Interestingly, the F-actin surface deposited significantly higher amounts of anti-C1q after the NHS incubation (Fig. 3; data group III), an observation that disappeared in C1q-depleted serum. Although the platelet morphology showed no apparent signs of activation, the cell count was higher on F-actin than on G-actin surfaces in NHS (Fig. 9). This support the observation by Vasconcellos and Lind ${ }^{31}$ who reported some platelet activation capacity by Factin.

\section{DISCUSSION}

Free actin in the extracellular space may have harmful and even toxic effects on cells. ${ }^{22}$ The present study suggests that surface bound actin is a relatively poor activator of the coagulation and complement systems and interacts moderately with neutrophils and platelets in vitro. However, we observed that C1q binds to immobilized F-actin, with a subsequent adhesion of platelets. The binding decreased dramatically in C1q-depleted serum. F-actin may be localized to interfaces between biomaterials and body fluids since: $i$ ) the insertion of a device induces tissue injury, ii) conditions that give rise to cell lysis are reported in biomaterial applications, iii) platelets and leukocytes adhere to surfaces during the acute phase of inflammation and form large amounts of intracellular F-actin, ${ }^{15-17}$ iv) foreign body giant cells that appear during a chronic inflammatory phase display distinct F-actin formations ${ }^{53}$ and $v$ ) fibroblasts use the actin cytoskeleton for orientation during the regenerative phase at biomaterial interfaces. ${ }^{54}$ Nishioka et al. observed a precipitation in a C1q-actin system, ${ }^{24}$ and the present study 
supports their observation in that association occurred when actin was surface bound, and was stronger for polymerized actin. The C1q-actin association was observed during typical extracellular osmotic conditions and may take part in the regulation of platelet adhesion.

C1q may bind to extracellular actin and act as a marker for C1q-receptor expressing cells. It was recently discovered that complement receptor 1 (CR1 or CD35, receptor for C3b, iC3b and C4b) also binds C1q. ${ }^{55}$ However, at least three other C1q-receptors have been identified: i) cC1qR or collectin receptor (60 kDa), ii) C1qRq (126 kDa) and iii) gC1qR (33 kDa), as reviewed by Peerschke and Ghebrehiwet. ${ }^{56-58}$ Neutrophils express the four types of C1q receptors and platelets display gC1qR (33 kDa) and cC1qR (60 $\mathrm{kDa}$ ). Platelets have been shown to utilize their C1q-receptors during the adhesion to C1q-coated surfaces. 59 The $33 \mathrm{kDa}$ receptor is unique in recognizing the globular heads of $\mathrm{C} 1 \mathrm{q}$, and the other three receptors are specific for the collagen-like region of the molecule. Platelet but not neutrophil adhesion to the present actin surfaces was sensitive to the presence of C1q. Perhaps this is a reflection of different utilization or expression of the receptors in response to C1q-epitopes exposed after surface binding. Furthermore, platelets likely adhere more rapidly than neutrophils, and if surface localized C1q is only transiently available for cell interactions, neutrophils may appear too late to become affected. The neutrophils that interacted with F-actin in the presence of NHS showed no apparent signs of activation and were not affected when C1q was depleted from serum. This is in sharp contrast to the neutrophil behavior on potent classical activator surfaces such as IgG-coated methylated glass 47,48 in serum containing media. The binding of other specific complement antibodies was moderate in the F-actin/NHS system. Hence, unlike IgG, F-actin likely binds C1q by the collagen-like region and present the globular heads to the cells. However, more studies need to be performed to ascertain whether the platelet $33 \mathrm{kDa}$ receptor is in fact involved in the interaction with C1q on F-actin, or not. Alternatively, the C1q-supported platelet adhesion may be due to binding to other surface active serum proteins, for instance other complement fragments and IgG.

F-actin but not IgG on gold bound significant amounts of anti-C1q after the NHS incubations. This is in agreement with earlier findings that IgG is a much more efficient classical activator on 
hydrophobic than on hydrophilic surfaces. On hydrophobic surfaces (such as the methylated silicon in the present study) IgG is not easily desorbed and may be denatured in a fashion that facilitates C1q-binding. IgG can also directly bind $\mathrm{C} 3^{60}$ and perhaps this explains why hydrophilic IgG-coated surfaces activate the complement without the initial transient antibody-detection of C1q. The low-activating albumin surface acquired sparse, but far from negligible, complement (anti-C3c) deposition after the serum incubation. It is important in this context to remember that protein-resistant surfaces are rare and not many surfaces withstand deposition of complement during prolonged static interactions with blood in vitro. It seems therefore more appropriate to divide materials into low, moderate and potent binders of complement and ascertain whether these are true activators or not through detection of late appearing complement cascade factors, such as the alternative C3-convertase stabilizer properdin, or C3-degradation fragments like C3d. Also, the antibody binding to adsorbed NHS layers on surfaces is not necessarily proportional to the amount of adsorbed antigen, and protein size, charge and flexibility largely determine the avidity of the antibody.

In conclusion, this study reveals that surface bound actin binds low amounts of complement proteins from serum and induces a relatively low activation of neutrophils and platelets. However, immobilized actin filaments recruit platelets and associates with $\mathrm{C} 1 \mathrm{q}$ in a way that facilitates platelet adhesion. The extracellular immunoregulatory capacity of actin is relevant for a better understanding of the basic inflammatory mechanisms involved in biomaterial-tissue interactions.

Kristina Orselius is acknowledged for technical support. This work was funded by the Biocompatible Materials Program and the Swedish Biomaterials Consortium (Swedish National Foundation for Strategic Research) and the Swedish Medical Research Council (grant number 71X-12668). 


\section{REFERENCES}

1 Vroman L, Adams AL. Identification of rapid changes at plasma-solid interfaces. J Biomed Mater Res 1969;3:43-67. Tang L, Eaton JW. Inflammatory responses to biomaterials. Am J Clin Pathol 1995;103:466-71. Cooper NR. Biology of the complement system. In: Gallin, JI and Snyderman, R, eds. Inflammation: Basic Principles and Clinical Correlates. Philadelphia: Lippincott Williams \& Wilkins, 1999. p. 281-315. human colostrum IgA and serum IgG immobilized on methylated silicon. J Biomed Mater Res 1997;35:81-92.

5 Chenoweth DE. Complement activation in extracorporeal circuits. Ann NY Acad Sci 1987;516:306-313.

6 Kazatchkine MD, Carreno MP. Activation of the complement system at the interface between blood and artificial surfaces. Biomaterials 1988;9:30-35.

7 Cheung AK, Parker CJ, Wilcox L, Janatova J. Activation of the alternative pathway of complement by cellulosic hemodialysis membranes. Kidney Int 1989;36:257-265.

8 Tengvall P, Askendal A, Lundström I. Complement activation by 3-mercapto-1,2-propanediol immobilized on gold surfaces. Biomaterials 1996;17:1001-1007.

9 Lhotta K, Wurzner R, Kronenberg F, Oppermann M, Konig P. Rapid activation of the complement system by cuprophane depends on complement component C4. Kidney Int 1998;53:1044-1051. Wetterö J, Askendal A, Bengtsson T, Tengvall P. On the binding of complement to solid artificial surfaces in vitro. Biomaterials 2001;23:981-991.

11 Stossel TP. Mechanical responses of white blood cells. In: Gallin, JI and Snyderman, R, eds. Inflammation: Basic principles and clinical correlates. Philadelphia: Lipincott Williams \& Wilkins, 1999. p. 663-679. Lind SE, Smith DB, Janmey PA, Stossel TP. Depression of gelsolin levels and detection of gelsolin-actin complexes in plasma of patients with acute lung injury. Am Rev Resp Dis 1988;138:429-434. 
Smith DB, Janmey PA, Lind SE. Circulating actin-gelsolin complexes following oleic acidinduced lung injury. Am J Pathol 1988;130:261-267. 1995;7:111-117.

Hartwig JH. Mechanisms of actin rearrangements mediating platelet activation. J Cell Biol 1992;118:1421-1442. Hagmann J. Pattern formation and handedness in the cytoskeleton of human platelets. Proc Nat Acad Sci 1993;90:3280-3283. dynamics in human neutrophils during adhesion and phagocytosis is controlled by changes in intracellular free calcium. Eur J Cell Biol 1993;62:49-58. 1987;70:524-530.

Dahl B, Schiodt FV, Rudolph S, Ott P, Kiaer T, Heslet L. Trauma stimulates the synthesis of Gcglobulin. Intensive Care Med 2001;27:394-399. McGrath JL, Hartwig JH, Kuo SC. The mechanisms of F-actin microenvironments depend on the chemistry of probing surfaces. Biophys J 2000;79:3258-3266.

Renault A, Lenne PF, Zakri C, Aradian A, C. V-B, Amblard F. Surface-induced polymerization of actin. Biophys J 1999;76:1580-1590.

Erukhimov JA, Tang ZL, Johnson BA, Donahoe MP, Razzack JA, Gibson KF, Lee WM, Wasserloos KJ, Watkins SA, Pitt BR. Actin-containing sera from patients with adult respiratory distress syndrome are toxic to sheep pulmonary endothelial cells. Am J Resp Critical Care Med 2000;162:288-294.

Haddad JG. Plasma vitamin D-binding protein (Gc-globulin): multiple tasks. J Steroid Biochem Mol Biol 1995;53:579-582. Biochem Biophys Res Commun 1982;108:1307-1312. 
Fechheimer M, Daiss JL, Cebra JJ. Interaction of immunoglobulin with actin. Mol Immunol 1979;16:881-888. Janmey PA, Lamb JA, Ezzell RM, Hvidt S, Lind SE. Effects of actin filaments on fibrin clot structure and lysis. Blood 1992;80:928-936. Smith DB, Janmey PA, Herbert TJ, Lind SE. Quantitative measurement of plasma gelsolin and its incorporation into fibrin clots. J Lab Clin Med 1987;110:189-195. Morimatsu T, Kawagoshi A, Yoshida K, Tamura M. Actin enhances the activation of human neutrophil NADPH oxidase in a cell-free system. Biochem Biophys Res Commun 1997;230:206210.

Babior BM. NADPH oxidase: an update. Blood 1999;93:1464-1476.

30 Seno T, Inoue N, Gao D, Okuda M, Sumi Y, Matsui K, Yamada S, Hirata K-i, Kawashima S, Tawa R, Imajoh-Ohmi S, Sakurai H, Yokoyama M. Involvement of NADH/NADPH Oxidase in Human Platelet ROS Production. Thromb Res 2001;103:399-409. Vasconcellos CA, Lind SE. Coordinated inhibition of actin-induced platelet aggregation by plasma gelsolin and vitamin D-binding protein. Blood 1993;82:3648-3657. Loos M, Trinder PKE, Kaul M. Factors of the classical pathway. In: Rother, K, Till, GO and Hänsch, GM, eds. The complement system. Heidelberg: Springer Verlag Berlin, 1998. p. 1-23. Kern W, Puotinen DA. Cleaning solutions based on hydrogen peroxide for use in silicon semiconductor technology. RCA Rev 1970;187-206.

Peters DA, Deckert CA. Removal of photoresist film residues from wafer surfaces. J Elechtrochem Soc 1979;883-886. Hermansson GT, Mallia AK, K. SP. Immobilized affinity ligand techniques. San Diego, CA: Academic Press, Inc., 1992. Weetall HH. Preparation of immobilized proteins covalently coupled through silane coupling agents to inorganic supports. Appl Biochem Biotechnol 1993;41:157-188. studies of macromolecular interactions at the liquid/solid interface. J Colloid Interface Sci 1987;119:203-210. 
McCrackin FL. (1969) in NBS Technical Note 479, Washington DC.

de Feijter JA, Benjamins J, Veer FA. Ellipsometry as a tool to study the adsorption of synthetic and biopolymers at the air-water interface. Biopolymers 1978;17:1759-1773.

Wälivaara B, Askendal A, Lundstrom I, Tengvall P. Blood protein interactions with titanium surfaces. J Biomaterials Sci, Polymer Ed 1996;8:41-48.

Tengvall P, Askendal A, Lundström I. Complement activation by IgG immobilized on methylated silicon. J Biomed Mater Res 1996;31:305-312.

Böyum A. Separation of white blood cells. Nature 1964;204:794-794.

Böyum A. Isolation of mononuclear cells and granulocytes from human blood. Isolation of monuclear cells by one centrifugation, and of granulocytes by combining centrifugation and sedimentation at 1 g. Scand J Clin Lab Invest Suppl 1968;97:77-89.

Ferrante A, Thong YH. Optimal conditions for simultaneous purification of mononuclear and polymorphonuclear leucocytes from human blood by the Hypaque-Ficoll method. J Immunol Methods 1980;36:109-117.

Bengtsson T, Grenegård M. Platelets amplify chemotactic peptide-induced changes in F-actin and calcium in human neutrophils. Eur J Cell Biol 1994;63:345-349.

Dahlgren C, Follin P, Johansson A, Lock R, Lundqvist H, Walan Å. Chemiluminescence as a means of following the function of phagocytic cells. Trends Photochem Photobiol 1991;427-443.

Wetterö J, Bengtsson T, Tengvall P. Complement activation on immunoglobulin G-coated hydrophobic surfaces enhances the release of oxygen radicals from neutrophils through an actindependent mechanism. J Biomed Mater Res 2000;51:742-751.

Wetterö J, Bengtsson T, Tengvall P. C1q-independent activation of neutrophils by immunoglobulin M-coated surfaces. J Biomed Mater Res 2001;57:550-558.

Wetterö J, Tengvall P, Bengtsson T. Platelets stimulated by IgG-coated surfaces bind and activate neutrophils through a selectin-dependent pathway. Biomaterials 2002 (submitted)

Waldeck DH, Alivisatos AP, Harris CB. Nonradiative dampening of molecular electronic excited states by metal surfaces. Surf Sci 1985;158:103-125. 
51 Zalavary S, Grenegård M, Stendahl O, Bengtsson T. Platelets enhance Fc(gamma) receptormediated phagocytosis and respiratory burst in neutrophils: the role of purinergic modulation and actin polymerization. J Leukocyte Biol 1996;60:58-68.

Nimeri G, Öhman L, Elwing H, Wetterö J, Bengtsson T. The influence of plasma proteins and platelets on oxygen radical production and F-actin distribution in neutrophils adhering to polymer surfaces. Biomaterials 2002;23:1785-1795.

DeFife KM, Jenney CR, Colton E, Anderson JM. Cytoskeletal and adhesive structural polarizations accompany IL-13-induced human macrophage fusion. J Histochem Cytochem 1999;47:65-74. Comut AA, Shortkroff S, Zhang X, Spector M. Association of fibroblast orientation around titanium in vitro with expression of a muscle actin. Biomaterials 2000;21:1887-1896.

55 Klickstein LB, Barbashov SF, Liu T, Jack RM, Nicholson-Weller A. Complement receptor type 1 (CR1, CD35) is a receptor for C1q. Immunity 1997;7:345-355. Peerschke EI, Ghebrehiwet B. Platelet membrane receptors for the complement component C1q. Sem Hematol 1994;31:320-328. Ghebrehiwet B, Peerschke EIB. Surface receptors and signalling pathways. In: Rother, K, Till, GO and Hänsch, GM, eds. The complement system. Heidelberg: Springer Verlag Berlin, 1998. p. 188210. Peerschke EI, Ghebrehiwet B. Human blood platelet gC1qR/p33. Immunol Rev 2001;180:56-64. Peerschke EI, Ghebrehiwet B. Platelet C1q receptor interactions with collagen- and C1q-coated surfaces. J Immunol 1990;145:2984-2988. Sahu A, Pangburn MK. Covalent attachment of human complement C3 to IgG. Identification of the amino acid residue involved in ester linkage formation. J Biol Chem 1994;269:28997-29002. 


\section{CAPTIONS}

\section{Table 1.}

Net serum and concomitant antibody depositions to pre-adsorbed protein layers on aminated silicon and

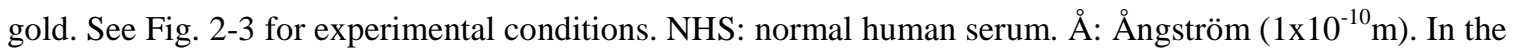
right column, the C1q-depleted serum was reconstituted with $180 \mu \mathrm{g} / \mathrm{mL}$ C1q.

\section{Fig. 1.}

Rapid actin polymerization onto an immobilized monolayer of G-actin on gold. The surfaces were mounted in a cuvette at $37^{\circ} \mathrm{C}$ and the surface-deposited mass was measured in situ by null ellipsometry. Clean gold surfaces were incubated for one hour in $0.1 \mathrm{mg} / \mathrm{mL}$ G-actin in $2.0 \mathrm{mM}$ Tris, $\mathrm{pH} 8.0$ (non-filled squares). After one hour, the osmotic conditions were changed by addition of $100 \mathrm{mM} \mathrm{KCl}$ and $2 \mathrm{mM} \mathrm{MgCl}_{2}$, resulting in a near threefold increase in the deposited mass (filled squares). The formed F-actin layer could not be removed by a 10.4 mM SDS-elution. Representative experiment.

\section{Fig. 2.}

Complement deposition from normal human serum (NHS) onto covalently immobilized G-actin (A), Factin (B), albumin (C) and IgG (D) on amino-propyl-triethoxysilane + glutaraldehyde (APTES + GA, figure E) on silicon. The surfaces were incubated in 10\% NHS in veronal buffered saline supplemented with $\mathrm{Mg}^{2+}$ and $\mathrm{Ca}^{2+}\left(\mathrm{VBS}^{2+}\right.$ ) for 5 (data group I) or 90 (group II) min, at $37^{\circ} \mathrm{C}$. The protein depositions were studied by null-ellipsometry. The samples were gently rinsed 4 times before each measurement. The subsequent binding from 1/50 dilutions of anti-C1q, anti-C3c, anti-C3d or anti-properdin, respectively, onto the adsorbed protein layers was followed. Bars indicates the SEM, $n=6-10$. 
Fig. 3.

F-actin surfaces bind C1q from normal human serum (NHS). Hydrophilic gold surfaces were coated with G-actin (data group I), F-actin (group II), albumin (group III) or IgG (group IV) and subsequently exposed

to $10 \% \mathrm{NHS}$ at $37^{\circ} \mathrm{C}$ in $\mathrm{VBS}^{2+}$ in situ during 5 min. Ellipsometric detection after the subsequent incubation

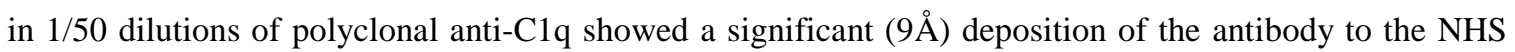
layer on F-actin. Bars indicate the SEM, $n=6$.

\section{Fig. 4.}

A monolayer of spontaneously adsorbed actin does not amplify the respiratory burst in neutrophils and platelets. Luminol-amplified chemiluminescence (CL) was measured in neutrophils (2 x 10\% $/ \mathrm{mL})$ and/or platelets $\left(1 \times 10^{8} / \mathrm{mL}\right)$ in $\mathrm{KRG}$ in the presence of horseradish peroxidase $(4 \mathrm{U} / \mathrm{mL})$ under non-stirring conditions at $37^{\circ} \mathrm{C}$ during 30 min in G-actin or non-coated hydrophobic glass tubes. CPM: counts per minute. Representative experiment.

\section{Fig. 5.}

The luminol-amplified chemiluminescence (CL) response from cells that contact G-actin coated particles does not differ from the response triggered by albumin-coated particles. Pre-warmed cells were stimulated with non-phagocytosable aminated silicon particles $\left(1 \times 10^{5} / \mathrm{mL}\right)$ with various glutaraldehyde-coupled protein coatings. Data from 15 min of CL under stirring conditions (700 rpm) in a two-sample LumiAggregometer in KRG in the presence of horseradish peroxidase $(4 \mathrm{U} / \mathrm{mL})$. Bars represent the SEM, a.u.: arbitrary unit.

(A) Representative CL-signal in the neutrophil system (2 x 10\%/mL). IgG-coated particles induced a semipotent ROS-generation, but the responses induced by G-actin and albumin, respectively, were close to baseline levels. 
(B) As in (A), but integrated values. No significant difference in the CL-response was found between Gactin and albumin-coated particles in a buffer system (first data set, $n=9$ ) or with $10 \%$ normal human serum added to the test system (second data set, $n=3$ ).

(C) Experiments performed as in (B), but with or without washed platelets $\left(1 \times 10^{8} / \mathrm{mL}\right)$ added. No significant differences were found between the G-actin and albumin surface induced CL-responses $(n=3)$.

\section{Fig. 6.}

The aggregation of neutrophils $\left(2 \times 10^{6} / \mathrm{mL}\right)$ and/or platelets $\left(1 \times 10^{8} / \mathrm{mL}\right)$ in KRG after stimulation with Gactin- or albumin coated silicon particles $\left(1 \times 10^{5} / \mathrm{mL}\right)$. The experiments were performed at $37^{\circ} \mathrm{C}$ in a Lumi-Aggegometer under stirring (700 rpm).

(A) Representative trace of platelet aggregation. G-actin and albumin surfaces triggered very low aggregation in comparison to IgG-coated particles.

(B) Averaged maximum aggregation after $15 \mathrm{~min}$. No significant differences were found between albumin and G-actin coated particles in platelet, neutrophil or mixed neutrophil-platelet suspensions. Bars indicate the SEM, $n=3$.

\section{Fig. 7.}

Actin coatings reduce the neutrophil spreading at surfaces. G- or F-actin were immobilized to gold and some of the surfaces were exposed to $5 \%$ NHS prior to the addition of $1 \times 10^{6} / \mathrm{mL}$ neutrophils. The samples were incubated for $20 \mathrm{~min}$ at $37^{\circ} \mathrm{C}$ in $\mathrm{KRG}$, fixed during $30 \mathrm{~min}$ in $4 \%$ paraformaldehyde, and permeabilized and stained for F-actin in lysophosphatidylcholine and bodipyphallacidin. The cell appearance was then documented by fluorescence microscopy. The presence of NHS showed no effect on the neutrophil morphology on G- or F-actin, but reduced the spreading on pure gold. The opposite occurred on the relatively potent complement activator surface IgG. No fluorescence was noted from bodipyphallacidin-stained cell-free actin-coated surfaces. Bar: $10 \mu \mathrm{m}$. 


\section{Fig. 8.}

Actin coatings reduce platelet spreading at surfaces. Platelets $\left(1 \times 10^{8} / \mathrm{mL}\right)$ were allowed to interact during 20 min with non-, G- or F-actin coated gold surfaces with or without 5\% C1q-depleted serum present at $37^{\circ} \mathrm{C}$ in KRG. The cells were then fixed, permeabilized, stained for intracellular F-actin with bodipyphallacidin and documented by fluorescence microscopy. The platelet adhesion was quantitatively lower after the addition of NHS (morphology as shown for the reconstituted depleted serum in figures to the right). Platelet adhesion to F-actin in diluted serum depended on C1q. When C1q-depleted serum was reconstituted by the addition of $180 \mu \mathrm{g} / \mathrm{mL} \mathrm{C1q}$ prior to interaction with surfaces, the F-actin surfaces recruited more platelets than when C1q was missing. This result was similar for mixed neutrophil-platelet suspensions. Bar: $10 \mu \mathrm{m}$.

\section{Fig. 9.}

C1q supports platelet adhesion to F-actin surfaces and more platelets adhere to F- than G-actin in serum containing solutions. The samples were prepared as in Fig. 8 and the platelets were exposed to C1qdepleted serum that was reconstituted, or not, with $180 \mu \mathrm{g} / \mathrm{mL}$ C1q. The number of adhered cells per view was counted using fluorescence microscopy at 630 x magnification. At least 25 views per sample were counted for each donor. The platelet count was higher on the reconstituted serum layers on F-actin than on C1q-depleted serum layers (for all donors, $\mathrm{p}=0.16$ ). Bars indicate the SEM, $n=4$. 


\section{Table 1}

\begin{tabular}{|c|c|c|c|c|}
\hline & \multicolumn{2}{|c|}{ Aminated silicon $(\AA)$} & \multicolumn{2}{|c|}{ Gold $(\AA)$} \\
\hline & $\begin{array}{l}\text { NHS } \\
(5 \mathrm{~min})\end{array}$ & $\begin{array}{l}\text { NHS } \\
(90 \mathrm{~min})\end{array}$ & $\begin{array}{l}\text { C1q-depleted } \\
(5 \mathrm{~min})\end{array}$ & $\begin{array}{c}\text { C1q-depleted + C1q } \\
(5 \mathrm{~min})\end{array}$ \\
\hline \multicolumn{5}{|l|}{ non-coated } \\
\hline serum & 24 & 43 & 51 & 41 \\
\hline anti-C1q & 10 & 11 & -5 & 9 \\
\hline anti-C3c & 11 & 50 & & \\
\hline anti-C3d & 2 & 18 & & \\
\hline anti-properdin & 0 & 3 & & \\
\hline \multicolumn{5}{|l|}{$\lg G$} \\
\hline serum & 9 & 40 & 3 & 5 \\
\hline anti-C1q & 12 & 9 & -5 & 1 \\
\hline anti-C3c & 19 & 62 & & \\
\hline anti-C3d & 4 & 19 & & \\
\hline anti-properdin & 1 & 7 & & \\
\hline \multicolumn{5}{|l|}{ albumin } \\
\hline serum & 19 & 36 & 22 & 20 \\
\hline anti-C1q & 13 & 7 & -5 & 10 \\
\hline anti-C3c & 11 & 43 & & \\
\hline anti-C3d & 3 & 14 & & \\
\hline anti-properdin & 0 & 2 & & \\
\hline \multicolumn{5}{|l|}{ G-actin } \\
\hline serum & 22 & 45 & 18 & 28 \\
\hline anti-C1q & 13 & 7 & 2 & 11 \\
\hline anti-C3c & 18 & 56 & & \\
\hline anti-C3d & 5 & 14 & & \\
\hline anti-properdin & -1 & 0 & & \\
\hline \multicolumn{5}{|l|}{ F-actin } \\
\hline serum & 11 & 18 & 6 & 18 \\
\hline anti-C1q & 9 & 5 & 2 & 27 \\
\hline anti-C3c & 7 & 46 & & \\
\hline anti-C3d & 6 & 12 & & \\
\hline anti-properdin & 0 & 0 & & \\
\hline
\end{tabular}


Figure 1

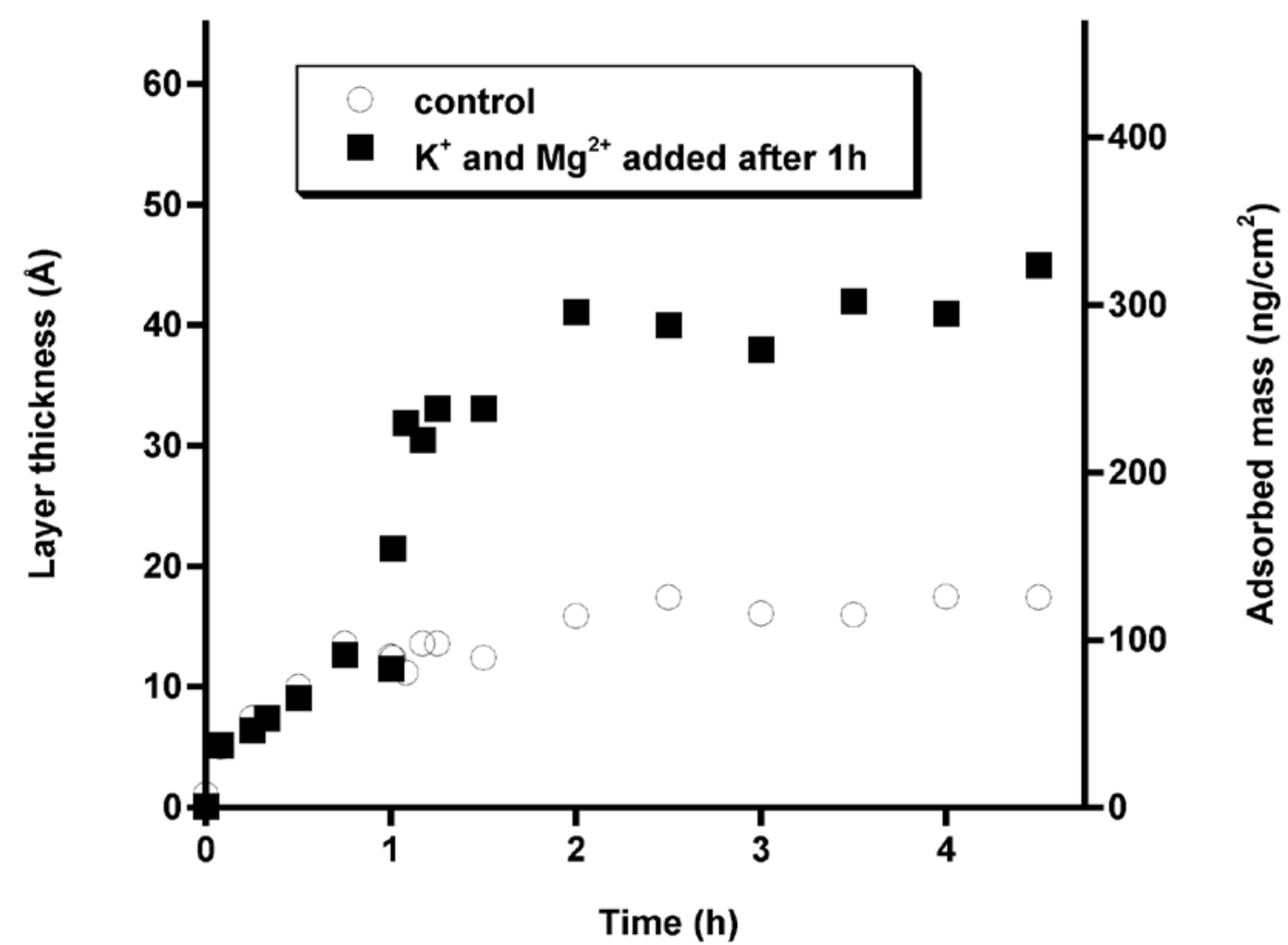


Figure 2A

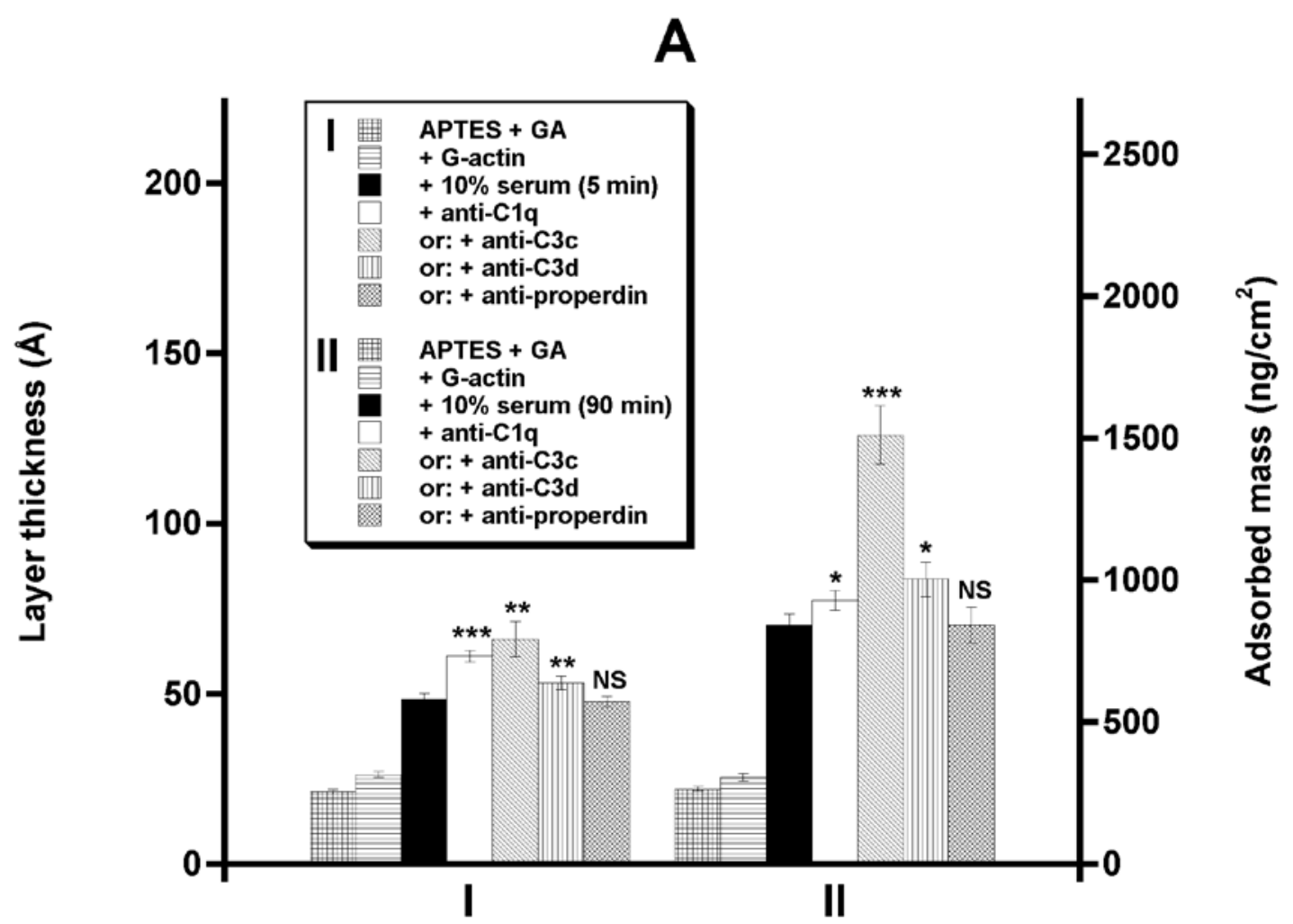


Figure 2B

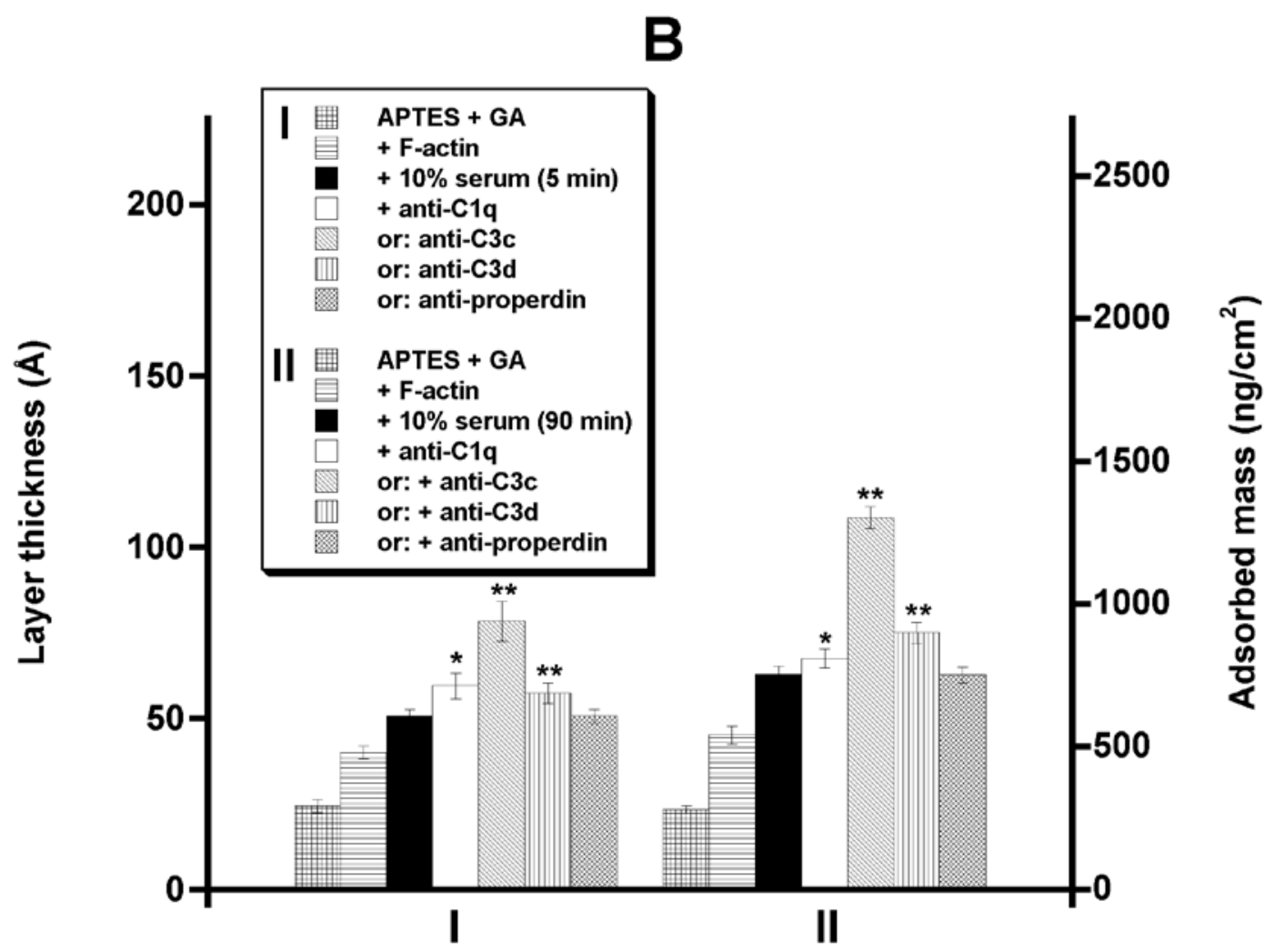


Figure 2C

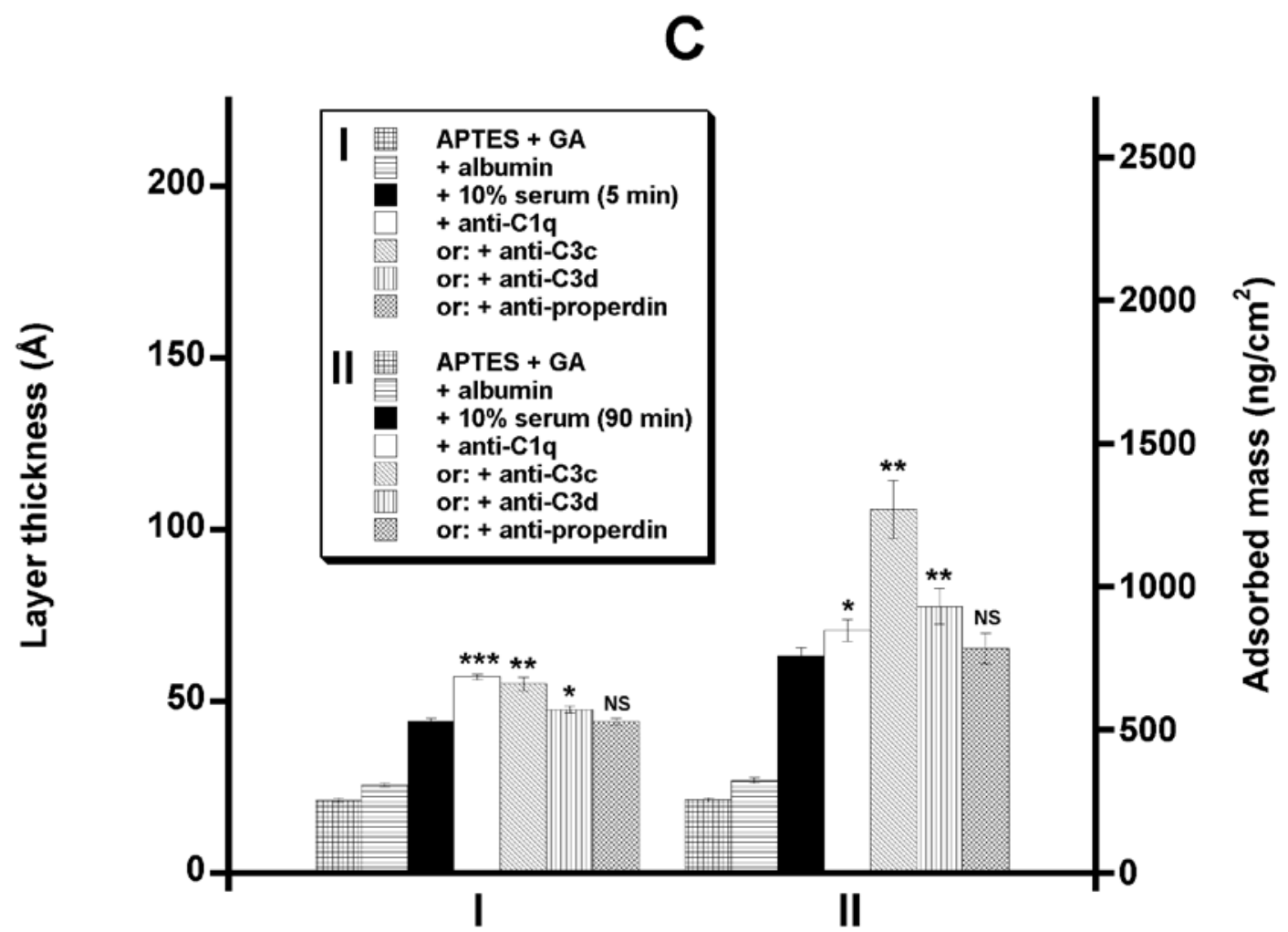


Figure 2D

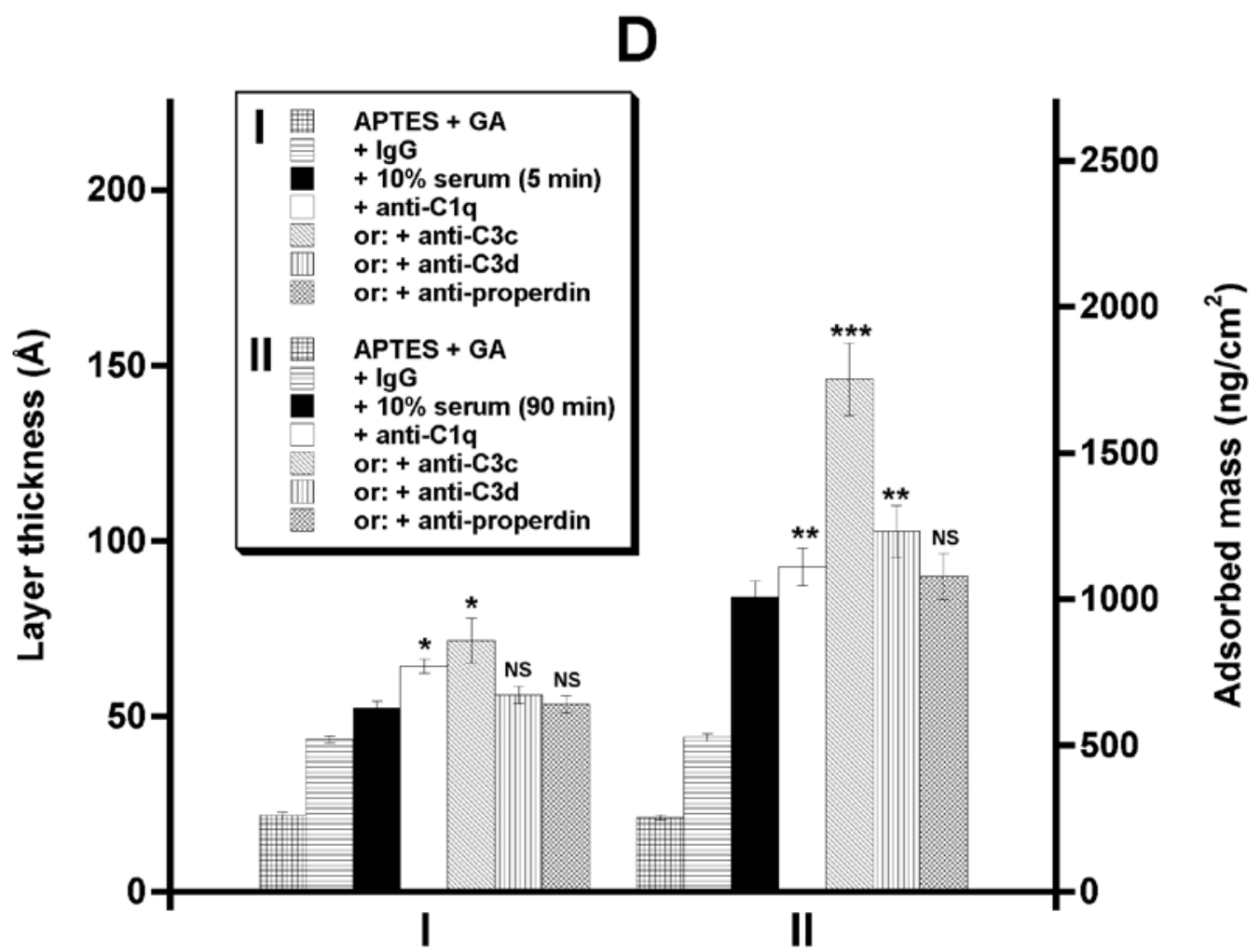


Figure 2E

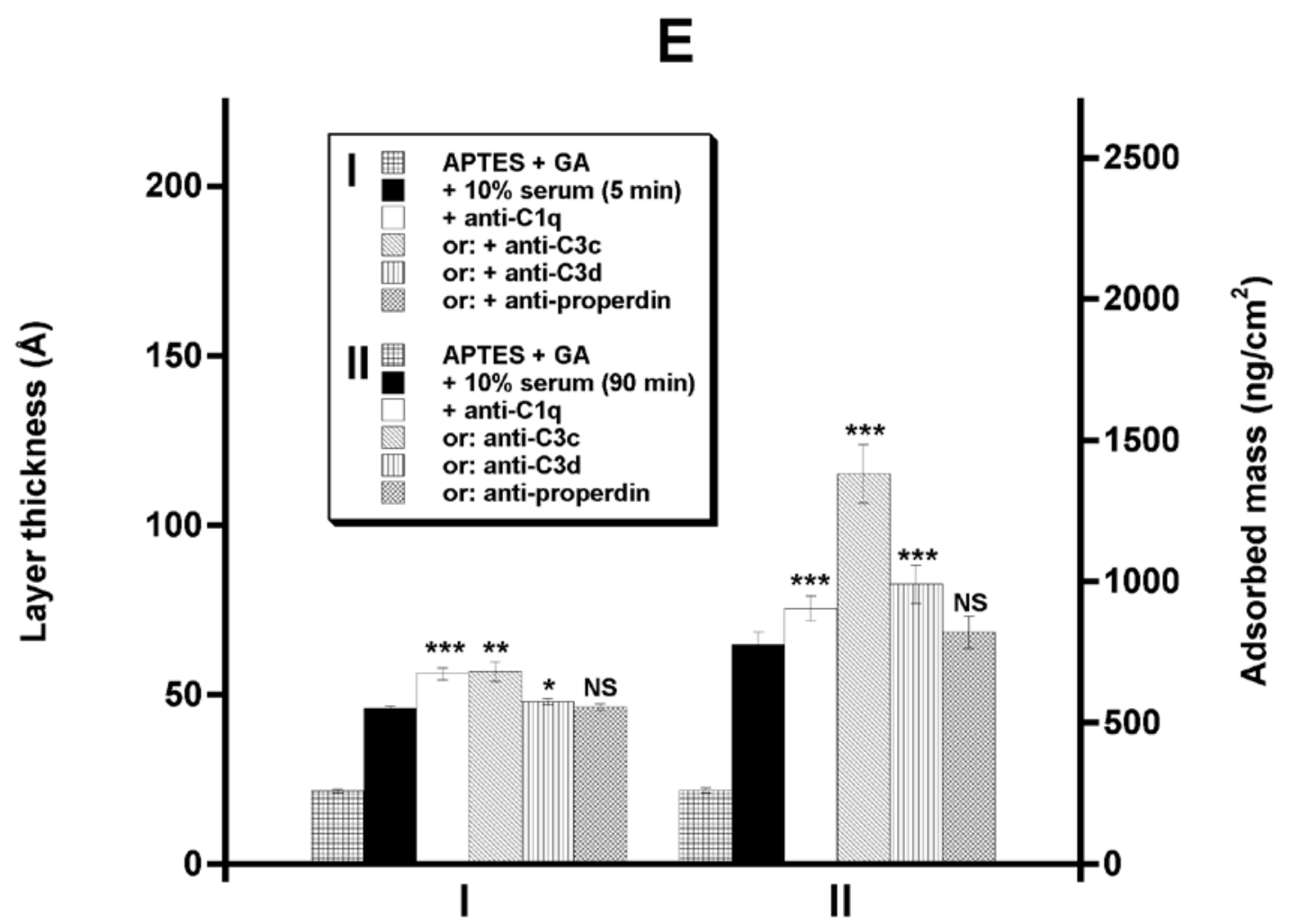


Figure 3

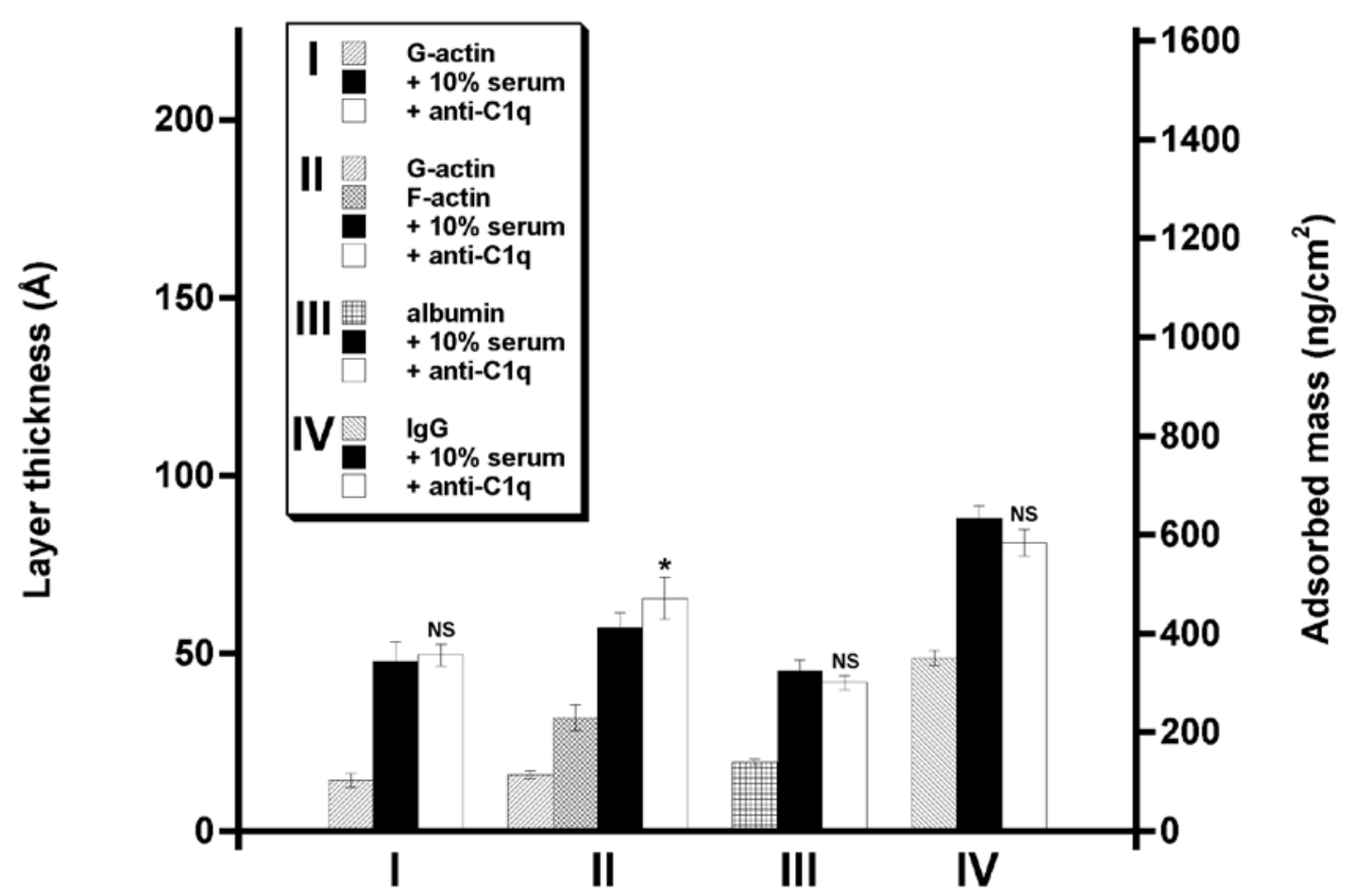




\section{Figure 4}

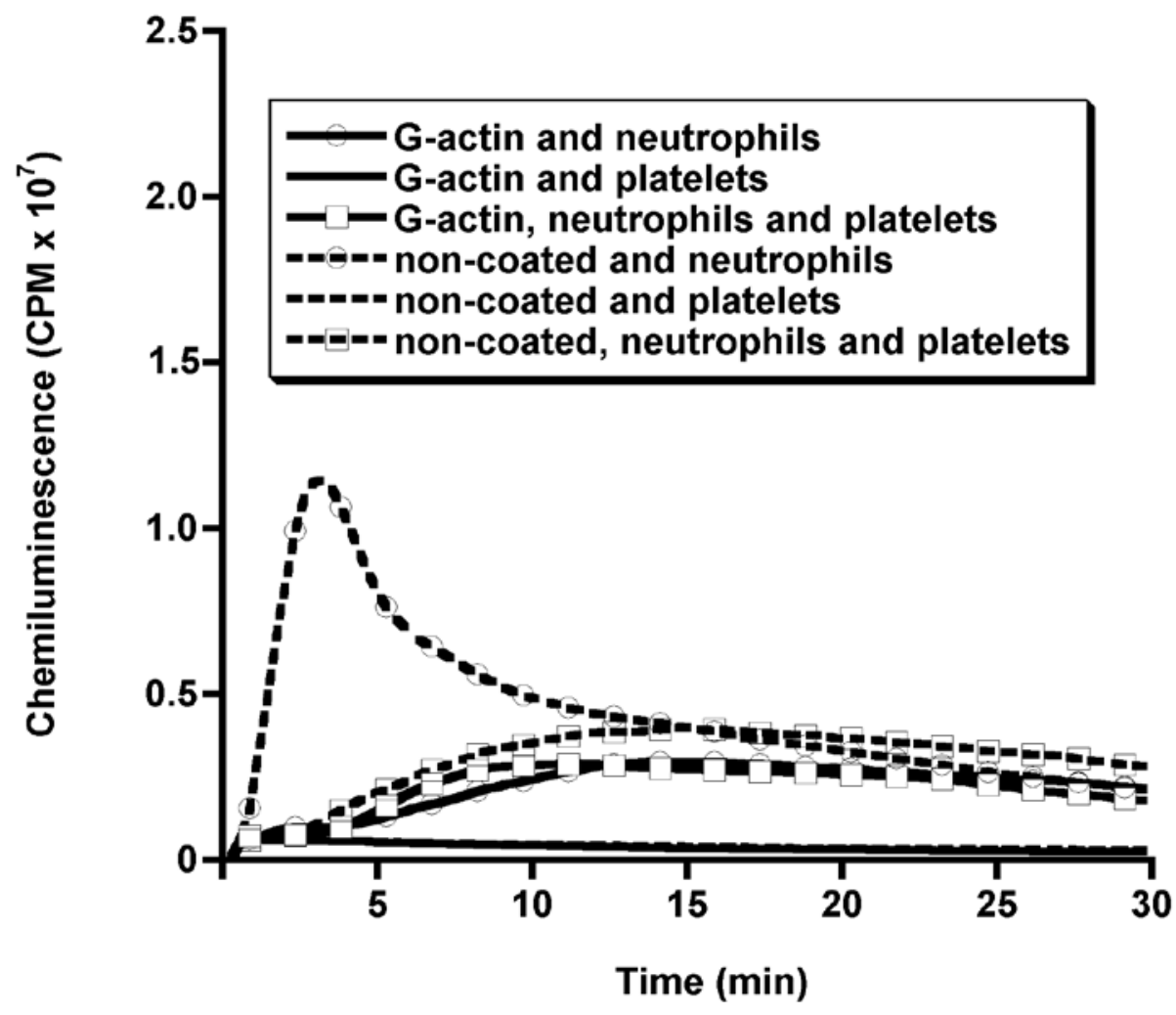


Figure 5A

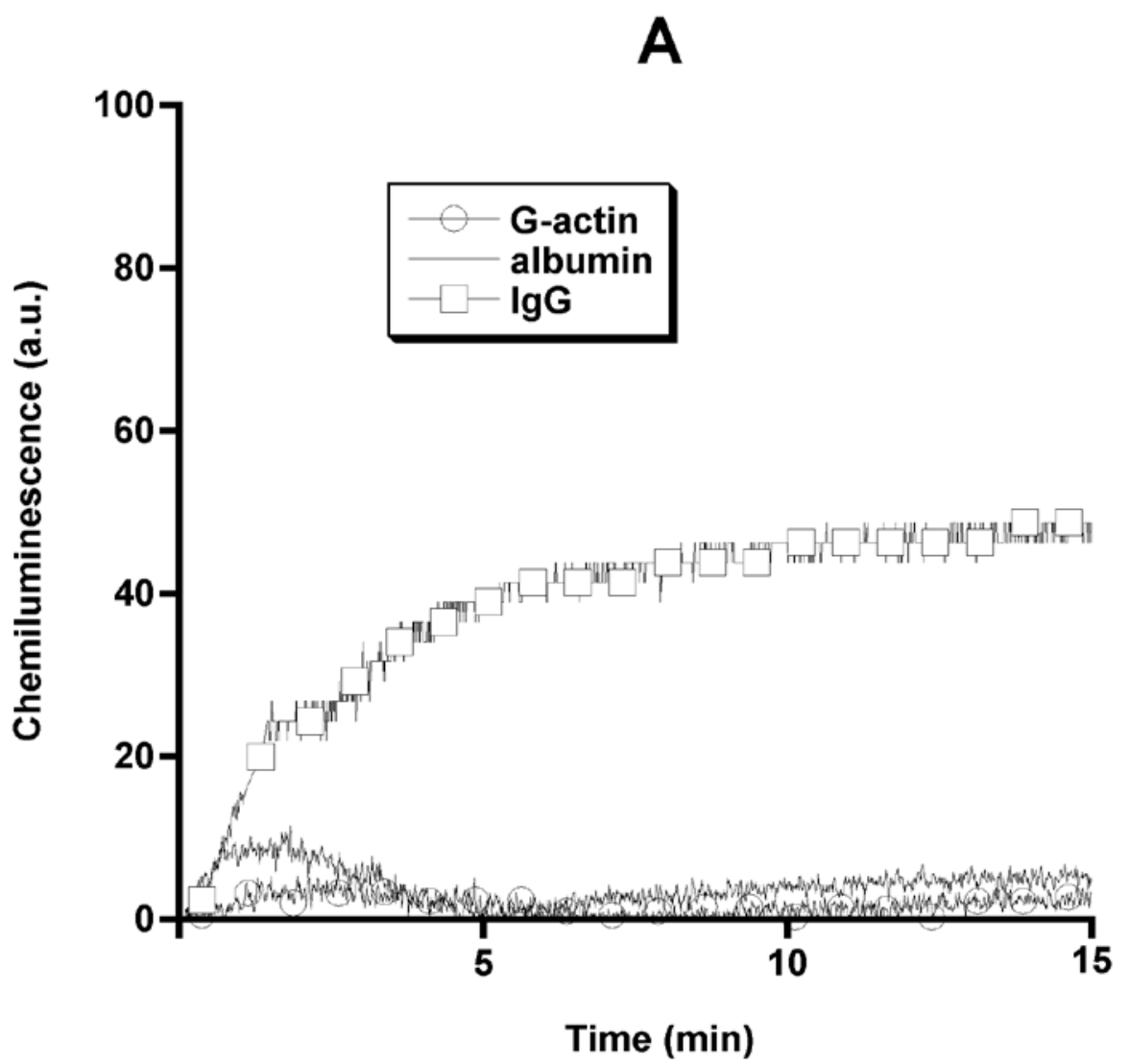


Figure 5B

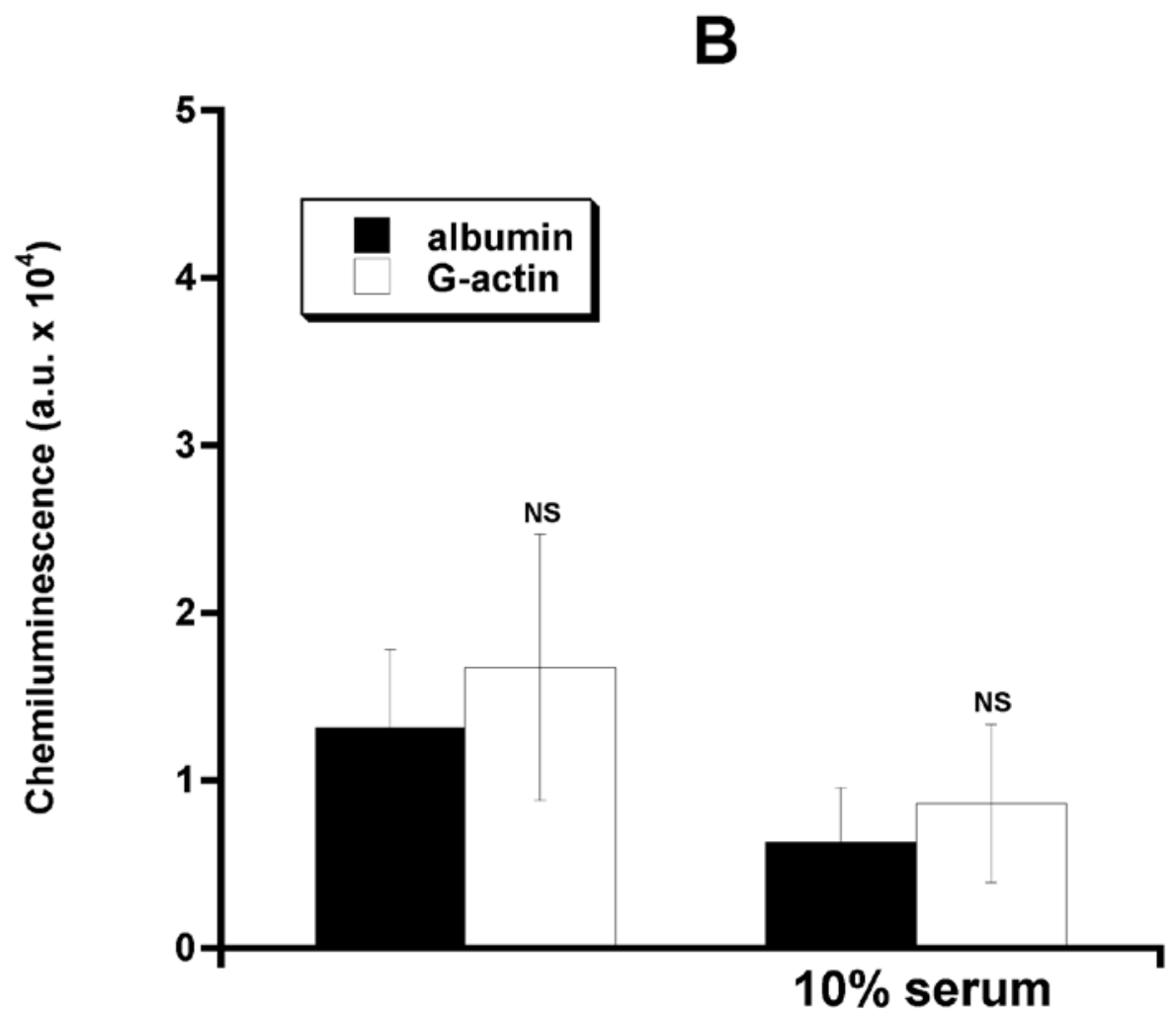


Figure 5C

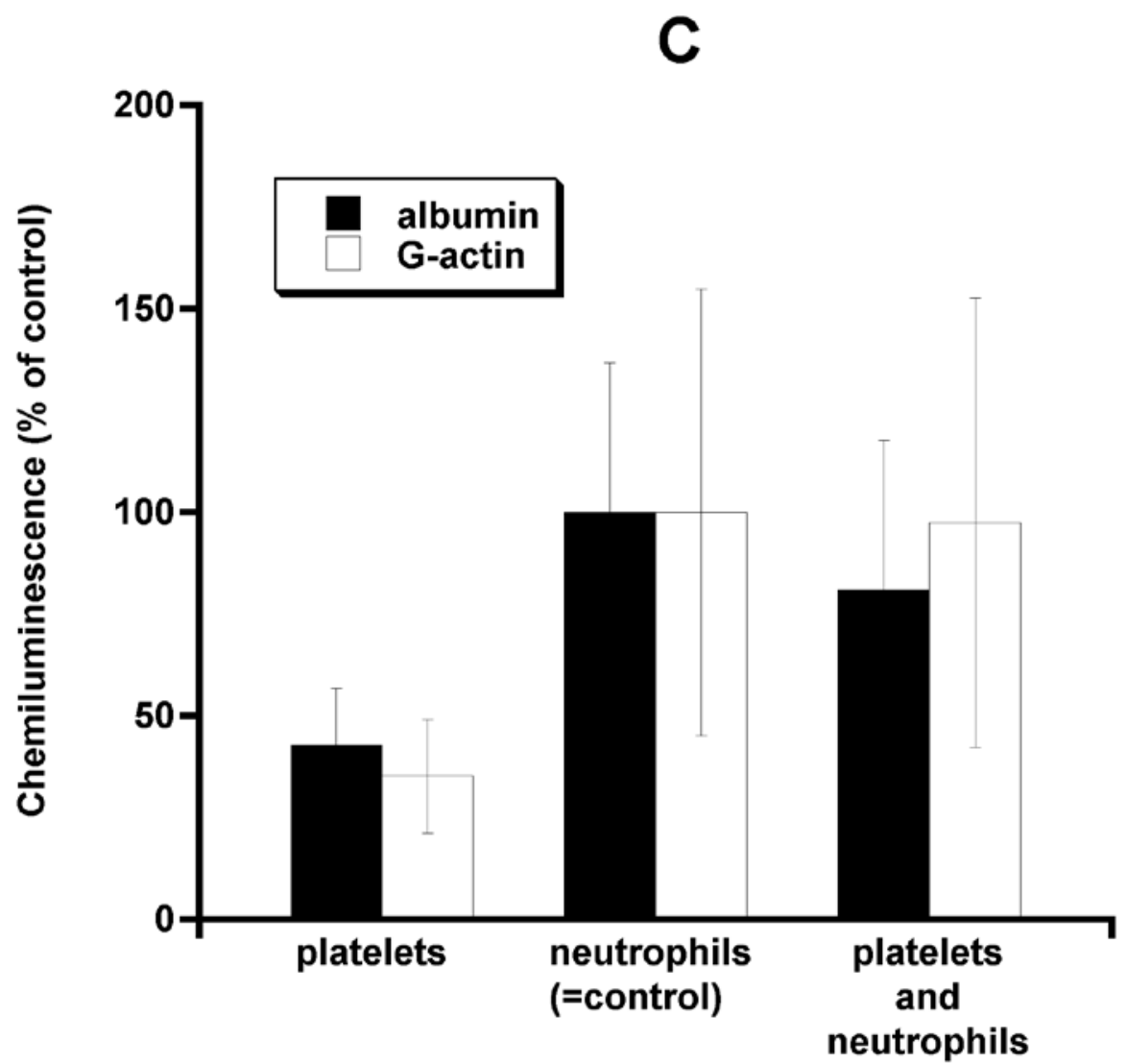


Figure 6A

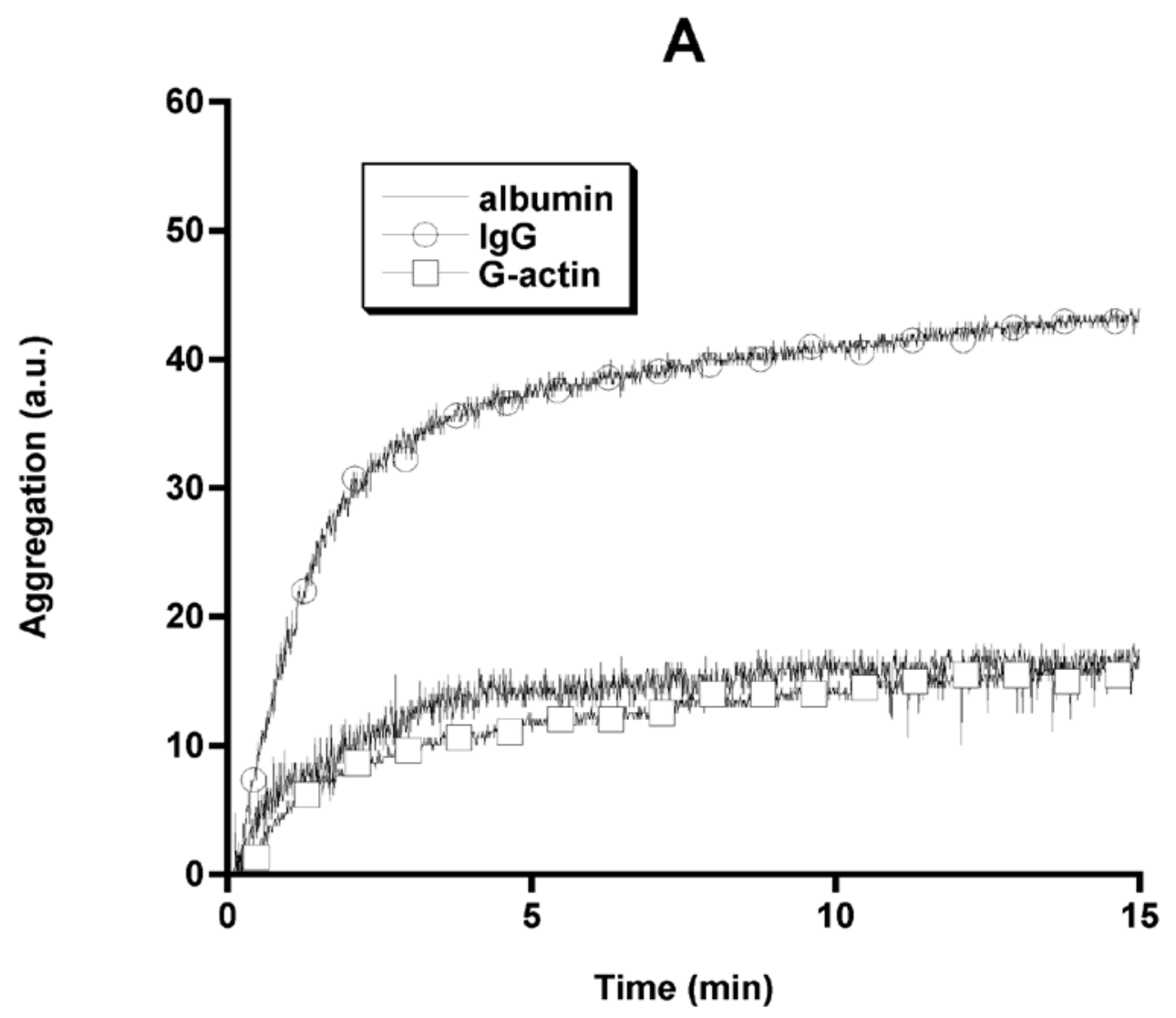


Figure 6B

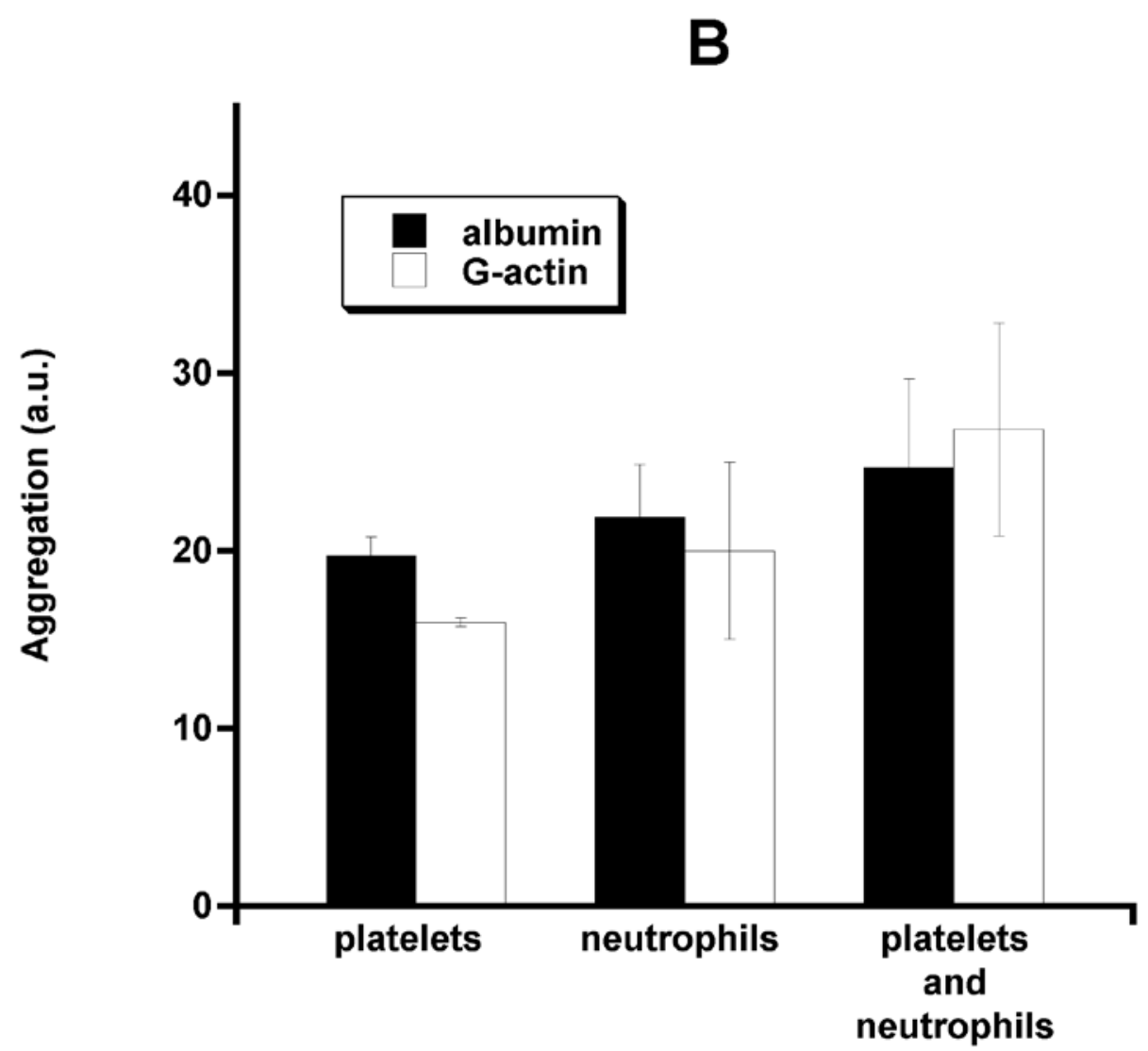




\section{Figure 7}

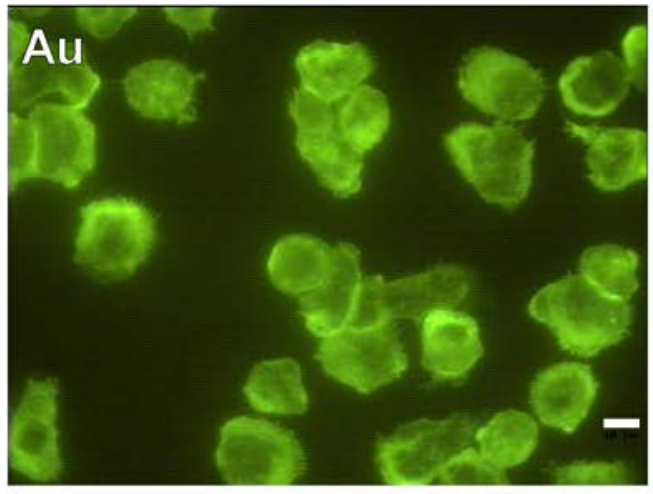

\section{Au and serum}
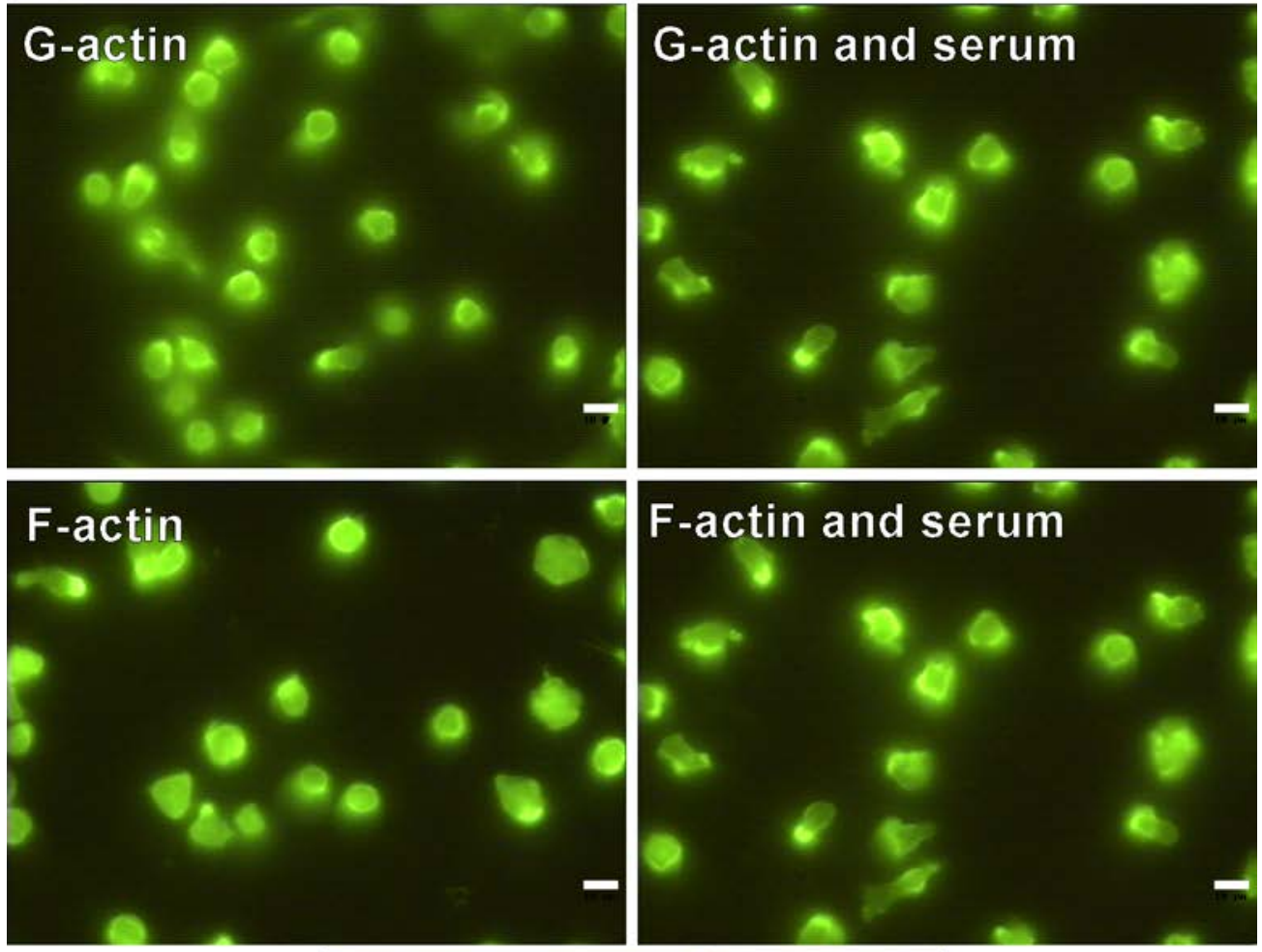

$\lg G$ and serum (reference)

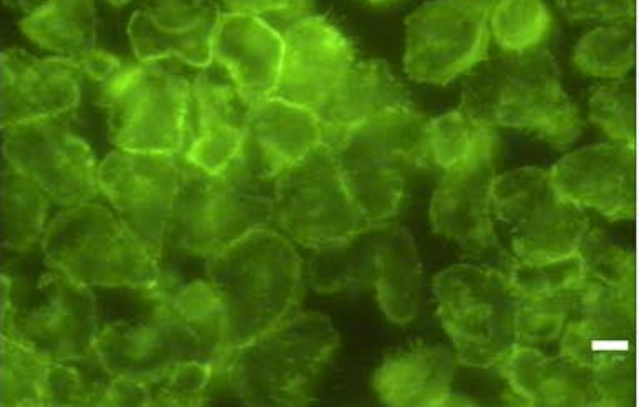




\section{Figure 8}
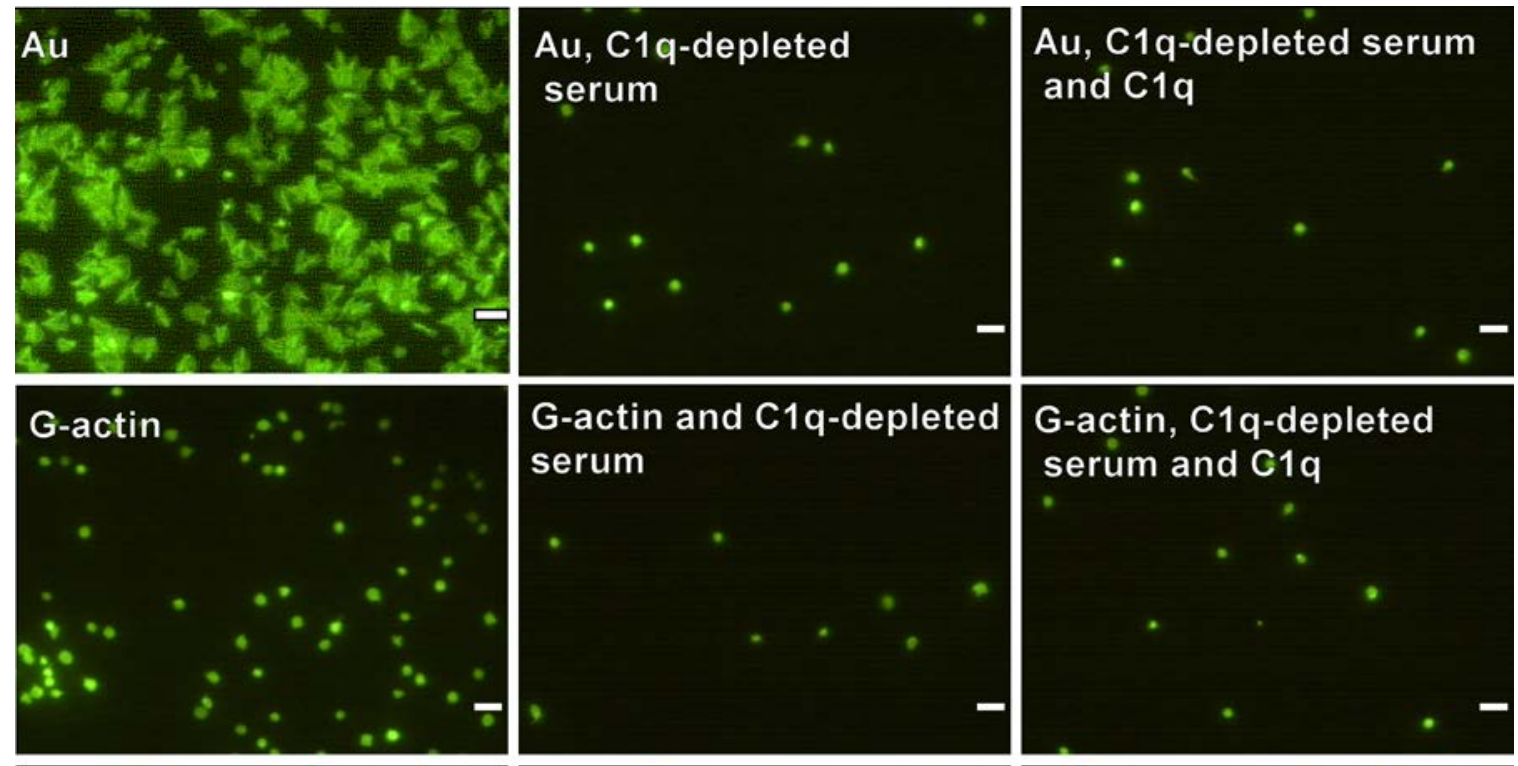
serum

G-actin, C1q-depleted serum and $\mathrm{C1q}$
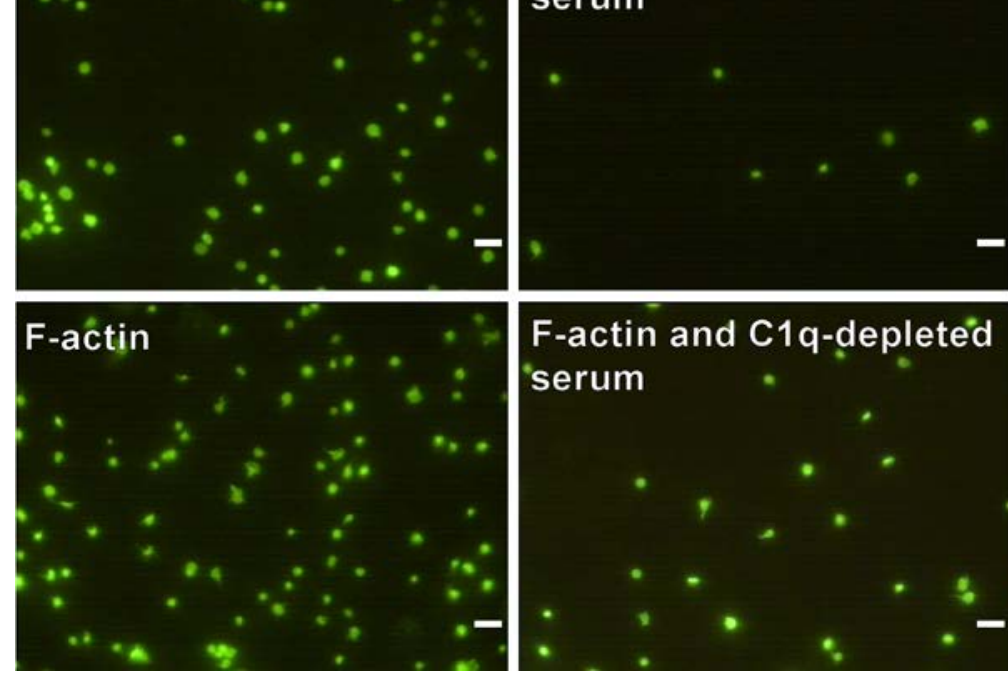

F-actin and C1q-depleted serum

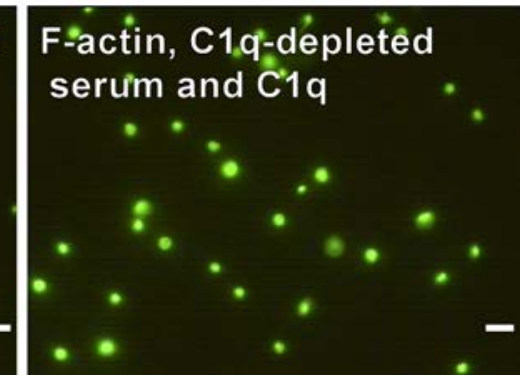


Figure 9

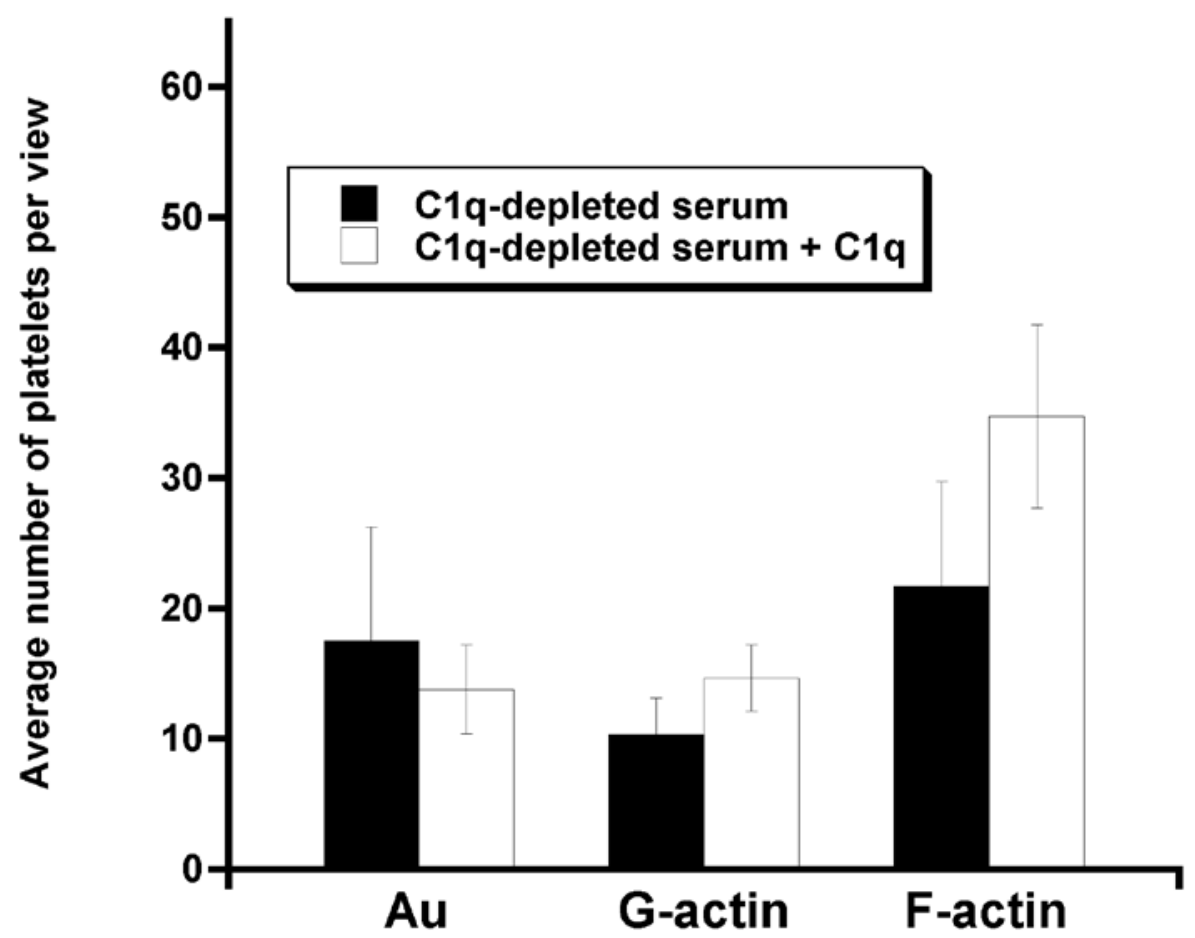

